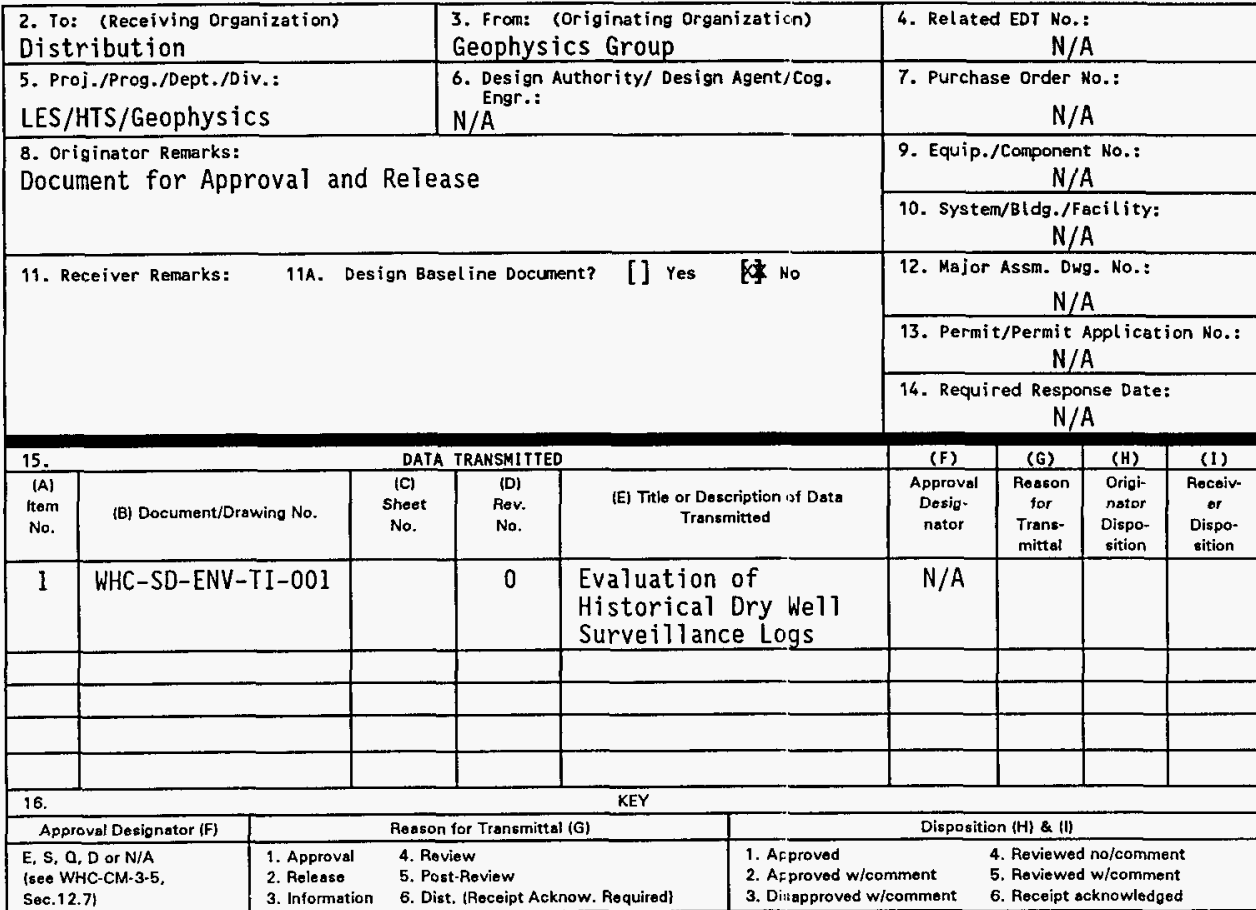

17. SIGNATURE/DISTRIBUTION

(See Approval Designator for required signat ures)

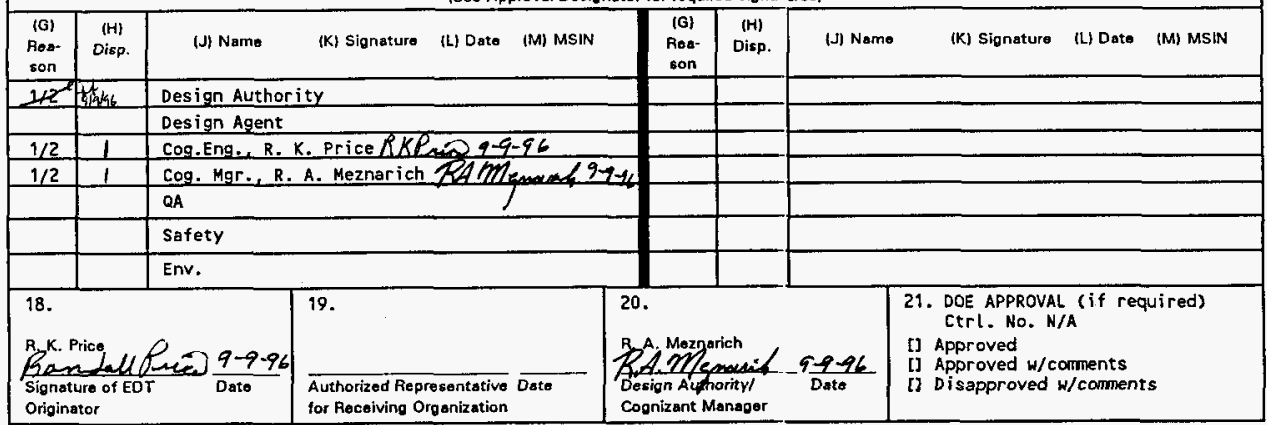

BD-7400-172-2(05/96) GEF097 


\section{Evaluation of Historical Dry Well Surveillance Logs}

R. K. Price,

West inghouse Hanford Company, Richland, WA 99352

U.S. Department of Energy Contract DE-ACO6-87RL10930

EDT/ECN: $\quad 610771$

Org Cade: $8 \mathrm{H} 340$

UC: 2000

B\&R Code: EW3120100

Charge Code: R4V11

Total Pages: 66

Key Words: borehole geophysics, in situ, moisture, moisture

calibration, monitoring, neutron moisture, Radionuclide

Logging System (RLS), subsurface, vadose zone

Abstract: Several dry well surveillance logs from 1975 through 1995 for the SX Tank Farm have been examined to identify potential subsurface zones of radioactive contaminant migration. Several dynamic conditions of the gamma-ray emitting radioactive contaminants have been identified.

TRADEMARK OISCLAIMER. Reference herein to any specific commercial product, process, or service by trade nane, trademark, manufacturer, or otherwise, does not necessarily constitute or imply its endorsement, recommendation, or favoring by the United States Goverment or any agency thereof or its contractors or subcontractors.

Printed in the United States of Anerica. To obtain copies of this document contact: WHC/BCS Document Control Services, P.O. Box 1970, Mailstop H6-08, fichtand Fax (509) 376-4989.
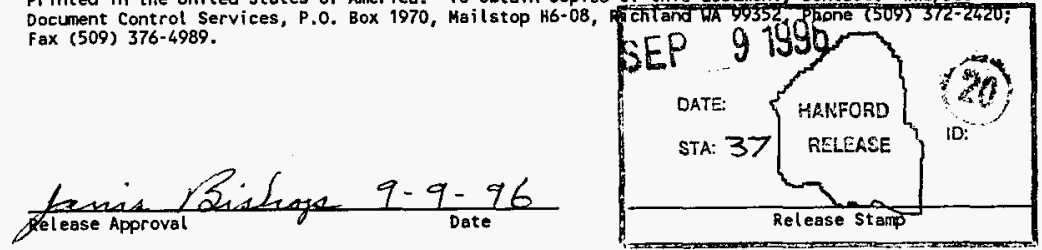

\section{Approved for Public Release}


WHC-SD-ENV-TI-001, Rev. 0

This page intentionally left blank. 


\section{CONTENTS}

1.0 INTRODUCTION $\ldots \ldots \ldots \ldots \ldots \ldots \ldots \ldots \ldots \ldots \ldots \ldots \ldots \ldots \ldots$

2.0 LIMITATIONS OF HISTORICAL SURVEILLANCE LOG DATA . . . . . . . . 1

3.0 SOFTWARE PROGRAM TO REVIEW HISTORICAL SURVEILLANCE LOGS . . . . . 2

4.0 EVALUATION OF HISTORICAL SURVEILLANCE LOGS $\ldots \ldots \ldots \ldots \ldots \ldots$

5.0 CONCLUSIONS AND RECOMMENDATIONS $\ldots \ldots \ldots \ldots \ldots \ldots \ldots \ldots$

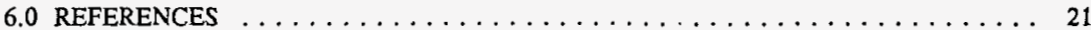

\section{APPENDICES}

A TANK FARM DRY WELL SURVEILLANCE LOGGING PROGRAM SUMMARY $\ldots \ldots$ A-1

B CONSIDERATIONS OF GEOPHYSICAL LOGGING EQUIPMENT AND ANALYSIS . . . B-1

C SOFTWARE PROGRAM FOR EXAMINING DRY WELL SURVEILLANCE LOGS $\ldots \ldots$ C-1

D SX 104-03 DRY WELL LOG DATA ANALYSIS $\ldots \ldots \ldots \ldots \ldots \ldots \ldots \ldots$

E SX $110-08$ DRY WELL LOG DATA ANALYSIS $\ldots \ldots \ldots \ldots \ldots \ldots \ldots \ldots$

\section{FIGURES}

1. Analysis of Surveillance Logs from Borehole $41-15-07 \ldots \ldots \ldots \ldots \ldots \ldots$

2. Analysis of Surveillance Logs from Borehole $41-14-09 \ldots \ldots \ldots \ldots \ldots \ldots \ldots$

3. Analysis of Surveillance Logs from Borehole $41-07-08 \ldots \ldots \ldots \ldots \ldots \ldots$

4. Analysis of Surveillance Logs from Borehole $41-00-08 \ldots \ldots \ldots \ldots \ldots \ldots \ldots$

5. Analysis of Surveillance $\operatorname{Logs}$ from Borehole $41-11-10 \ldots \ldots \ldots \ldots \ldots \ldots \ldots \ldots$

6. Analysis of Surveillance Logs from Borehole $41-09-09 \ldots \ldots \ldots \ldots \ldots \ldots \ldots$

7. Analysis of Surveillance Logs from Borehole $41-02-02 \ldots \ldots \ldots \ldots \ldots \ldots \ldots \ldots$

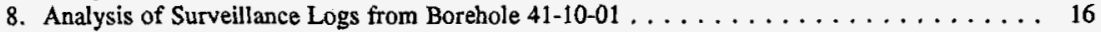

9. Analysis of Surveillance $\operatorname{Logs}$ from Borehole $41-04-03 \ldots \ldots \ldots \ldots \ldots \ldots \ldots \ldots$

10. Analysis of Surveillance Logs from Borehole $41-10-08 \ldots \ldots \ldots \ldots \ldots \ldots$

11. Filtered Data from Borehole 41-10-08 Compared to Ru-106 Decay . . . . . . . . . . 20

C-1. TFGROSS Input Parameters $\ldots \ldots \ldots \ldots \ldots \ldots \ldots \ldots \ldots \ldots \ldots \ldots \ldots$ 
WHC-SD-ENV-TI-001, Rev. 0

TABLES

1. Borehole Analysis by the TFGROSS Program $\ldots \ldots \ldots \ldots \ldots \ldots \ldots \ldots \ldots$

A-1. Dry Well Surveillance Logging Activity Summary $\ldots \ldots \ldots \ldots \ldots \ldots \ldots \ldots$

\section{LIST OF TERMS}

DOE U.S. Department of Energy

GM Geiger-Mueller

HPGe Hyper-Pure germanium

UO unusual occurrence 
WHC-SD-ENV-TI-001, Rev, 0

\section{EVALUATION OF HISTORICAL DRY WELL SURVEILLANCE LOGS}

\subsection{INTRODUCTION}

High-resolution germanium (HPGe) passive spectral gamma-ray surveys have been acquired in the vadose zone boreholes within the SX Tank Farm (U.S. Department of Energy [DOE 1996]) at the Hanford Site, near Richland, Washington. These borehole surveys will be the baseline against which future monitoring surveys will be compared. The HPGe baseline surveys also provide the opportunity to interpret the historical Tank Farm borehole survey logs.

During the preparation of the field activity report for the 241-SX-109 single-shell tank (DOE 1995b), changes in the gamma-ray activity that had been previously unreported were identified in the Dry Well surveillance logs from 1986 through 1989 for borehole 41-(09-09. These changes in gamma-ray activity indicated a dynamic condition in the subsurface.

The possibility of other dynamic conditions having been recorded by the Dry Well surveillance logs initiated this review of the historical survey data. (Dry Well surveillance logs are commonly called gross gamma-ray logs). Several dynamic conditions have been identified and will be discussed in this report.

The purpose of this report is to present a method by which the historical surveillance logs can be evaluated for indications of changes in the vadose zone contaminant plumes that are not attributable to radioactive decay. The review is limited to ten of the 95 vadose zone boreholes and groundwater wells within the SX Tank Farm. The borehole selection criteria is described later with the evaluation of the historical surveillance logs.

Identifying the source of the radioactive contaminants within the vadose zone, the migration pathway, and the mechanism of migration is beyond the scope of this report.

The report discusses: (1) the pedigree (limitations) of the historicial surveillance logs, (2) the processing options of a software program written to summarize the hundreds of surveys for a single borehole, and (3) the results of the surveillance log evaluation. Conclusions and recommendations are also provided.

\subsection{LIMITATIONS OF HISTORICAL SURVEILI_ANCE LOG DATA}

Tank leak detection was the objective of the Tank Farms Dry Well surveillance logging program from 1975 through 1995. A summary of the surveillance logging program is discussed in Appendix A. Additionally, Appendix B includes a general summary of borehole geophysical logging equipment and analysis considerations for measuring the subsurface gamma-ray radiation. The tank leak detection program was adequate for the type of tank failure for which it was designed (ie. rapid release of at least $19,000 \mathrm{~L}$ ( $5000 \mathrm{gal})$ of liquid into the subsurface soils).

However, significant limitations of both the accuracy and precision of the Dry Well surveillance logs restrict their use for environmental monitoring and contaminant pluıne tracking. Environmental monitoring and plume tracking is characterized by slow transport of the contaminants through the 
subsurface. The summaries (Appendices A and B) show that several variables within the logging program could severely limit the pedigree of the logs for environmental monitoring (e.g., multiple logging trucks, multiple probes with questionable calibration, and no tracking of the truck and probe combinations used to acquire each survey).

This report shows that some limited value can be attributed to the historical leak detection surveillance logs for environmental monitoring and identifying dynamic zones of radioactive contamination.

\subsection{SOFTWARE PROGRAM TO REVIEW HISTORICAL SURVEILLANCE LOGS}

A software program (TFGROSS ${ }^{1}$ ) was written to evaluate the historical Tank Farms Dry Well leak detection log data. To enable review of several hundred log surveys for a single borehole, the program corrected errors within a survey $\log$ and performed calculations to compress the survey log data into representative numeric values. The details of the software program are discussed in Appendix C.

The Dry Well survey files for selected boreholes were copied from their storage location on the server computer to a local analysis computer while protecting the original survey data values.

The program was used to identify invalid survey data values and replace them with a representative value from the adjacent valid survey measurements. A program option was used to normalize (depth shift) the surveys to a common gamma-ray feature within each su vey. Finally, the program was used to compute the net gamma-ray activity (grade thickness product) of the contamination intervals within each survey. The computed results are presented in Section 4.0 of this report.

An improvement of the data analysis is recommended. On each survey date, multiple boreholes were surveyed with a combination of one truck, one probe, and one setring of the electronic instrumentation. If all the surveys on a single date are above or below the average for all the boreholes surveyed, it would be reasonable to normalize all the surveys of the single date and apply a correction to each survey acquired. These additional analysis enhancements should be investigated to identify if they improve the computed results.

\subsection{EVALUATION OF HISTORICAL SURVEILLANCE LOGS}

Boreholes were selected for review based on the baseline survey acquired with the HPGe detector. The baseline logs are presented in the SX Tank Farm summary data reports referenced in DOE 1996. The boreholes selected generally contained zones of contamination below the base of the tanks

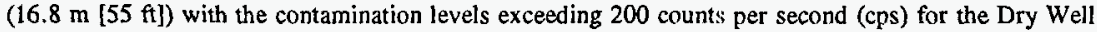
surveillance logs. Boreholes with high levels of contamination (preventing use of the sodium-iodide detector, probe type 4) generally were not selected for review in this report. The boreholes selected, the logging probe type, the first and last survey date, and the total number of surveys are presented in Table 1.

'TFGROSS is a software program developed by Westinghouse Hanforid Company. 
Table 1. Borehole Analysis by the TFGROSS Program.

\begin{tabular}{|c|c|c|c|c|}
\hline Borehole & Probe Type & $\begin{array}{c}\text { Date First } \\
\text { Survey }\end{array}$ & $\begin{array}{l}\text { Date Last } \\
\text { Survey }\end{array}$ & $\begin{array}{c}\text { Survey } \\
\text { Count }\end{array}$ \\
\hline $41-00-08$ & $4=\mathrm{NaI}$ & $1 / 15 / 1975$ & $10 / 19 / 1993$ & 208 \\
\hline $41-02-02$ & $4=\mathrm{NaI}$ & $1 / 14 / 1975$ & $7 / 26 / 1995$ & 896 \\
\hline $41-04-03$ & $4=\mathrm{NaI}$ & $1 / 14 / 1975$ & $11 / 22 / 1995$ & 601 \\
\hline $41-07-08$ & $4=\mathrm{Nal}$ & $1 / 15 / 1975$ & $6 / 9 / 1994$ & 279 \\
\hline $41-09-09$ & $\begin{array}{c}4=\mathrm{NaI} \\
14=\text { Shielded }\end{array}$ & $\begin{array}{l}1 / 15 / 1975 \\
7 / 14 / 1987\end{array}$ & $\begin{array}{l}6 / 9 / 1994 \\
6 / 9 / 1994\end{array}$ & $\begin{array}{r}319 \\
71\end{array}$ \\
\hline $41-10-01$ & $4=\mathrm{NaI}$ & $1 / 15 / 1975$ & $6 / 9 / 1994$ & 254 \\
\hline $41-10-08$ & $4=\mathrm{NaI}$ & $1 / 15 / 1975$ & $6 / 10 / 1994$ & 217 \\
\hline $41-11-10$ & $\begin{array}{c}1=\mathrm{GM}-\text { Green } \\
2=\mathrm{GM}-\text { Red } \\
4=\mathrm{NaI} \\
14=\text { Shielded }\end{array}$ & $\begin{array}{c}11 / 29 / 1979 \\
1 / 15 / 1975 \\
1 / 15 / 1965 \\
5 / 25 / 1977\end{array}$ & $\begin{array}{l}6 / 10 / 1994 \\
6 / 10 / 1994 \\
7 / 16 / 1980 \\
7 / 25 / 1980\end{array}$ & $\begin{array}{r}41 \\
131 \\
93 \\
6\end{array}$ \\
\hline $41-14-09$ & $4=\mathrm{NaI}$ & $1 / 15 / 1975$ & $6 / 9 / 1994$ & 184 \\
\hline $41-15-07$ & $4=\mathrm{NaI}$ & $1 / 15 / 1975$ & $6 / 9 / 1994$ & 84 \\
\hline
\end{tabular}

The data computed by the TFGROSS program is presented graphically as data plots. The monitoring surveys for each borehole analyzed are summarized into a single figure. Each figure contains three plots.

Two of the plots (left most and right most) are the first and last sucvey (e.g., 1975 and 1994) for the borehole being analyzed. These plots bave two linear $\mathrm{x}$-axis scales for presenting the measured gamma-ray activity (counts per second, cps) for visualizing both the background activity and the activity of the contaminated area. The narrow-line of the gamma-ray data plot uses the top scale of 0 to $200 \mathrm{cps}$. The wide-line data plot uses the bottom scale, which changes with each borehole analyzed. 
The center plot in each analysis figure is a summary of the multiple borehole surveys. The $x$-axis of the analysis summary plot indicates the survey year, from 1975 through 1995 . The computed results of each survey are plotted as dots (or other simple symbols). The small dots are the average background for each survey (i.e., AVGBKG variable described in Appendix C). The background activity of each survey is plotted against the right scale of 0 to $100 \mathrm{cps}$. The large dots represent the grade thickness product (ft-counts/sec) for each survey and are plotted against the left scale, which varies for each borehole analyzed. The grade thickness product is the net-contamination which is a sum of the detector count-rate for the contamination zone above the background activity. The netcontamination calculation is described in Appendix C.

Much of the scatter in the grade thickness product is from counting statistics. Frequently, when the surveys are acquired annually the seatter is greater than would be expected for counting statistics. A possible cause of the excessive scatter is that different logging trucks were used for the annual surveys and the different instruments contributed to the survey differences. This problem will be investigated further.

The analysis results are not presented by borehole number. The presentation order is according to the complexity of interpretation, from the simple to the complex and from the obvious to the subtle.

\subsection{BOREHOLE 41-15-07}

Borehole 41-15-07 contains one zone of contamination at $17.7 \mathrm{~m}(58 \mathrm{ft})$, Figure 1. The first survey $(1 / 15 / 75)$ is plotted on the left. The maximum measured gamma-ray activity is $453 \mathrm{cps}$. The contamination interval is defined by five data values $(93+238+453+325+85)$ with a summed net peak area (grade thickness product) of $1072 \mathrm{cps}$. The grade thickness product is plotted using the left scale of 0 to 2000 . The background for the first survey is $24.5 \mathrm{cps}$ and is plotted with the right scale of 0 to 100 .

The computed background and grade thickness product for each survey (from 1975 through 1994) are shown in the plot. The background and grade thickness product indicate that some instrumentation problems were present on several of the surveys acquired during 1975, as shown by the anomalous values.

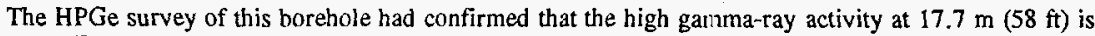
from ${ }^{137} \mathrm{Cs}$. The time rate of decay $\left(30.2\right.$ years) of ${ }^{137} \mathrm{Cs}$ is shown on the plot as a narrow-line. Some spread between the rate of decay line and the measured activity is expected from the counting statistics of the borehole surveys. The counting statistics of the Dry Well surveillance logs were computed but were not presented in this report. The variations observed are greater than counting statistics.

The source of the large variation and the net-contamination area are probably variations from the logging equipment, which can easily encompass the spread observed in the data. Appendix A noted that there were several logging vehicles and that the detectors were subject to failures within the 20year service time, which required replacing, at a minimum, the sodium-iodide crystal.

The conclusion, regardless of the uncertainty introduced from counting statistics and the variations within the measuring equipment, is that the contamination plume at $17.7 \mathrm{~m}(58 \mathrm{ft})$ in borehole 41-15-07 is not moving, is stable, and is decaying in place, at least within the system variance. 
WHC-SD-ENV-TI-001, Rev. 0

Figure 1. Analysis of Surveillance Logs from Borehole 41-15-07.

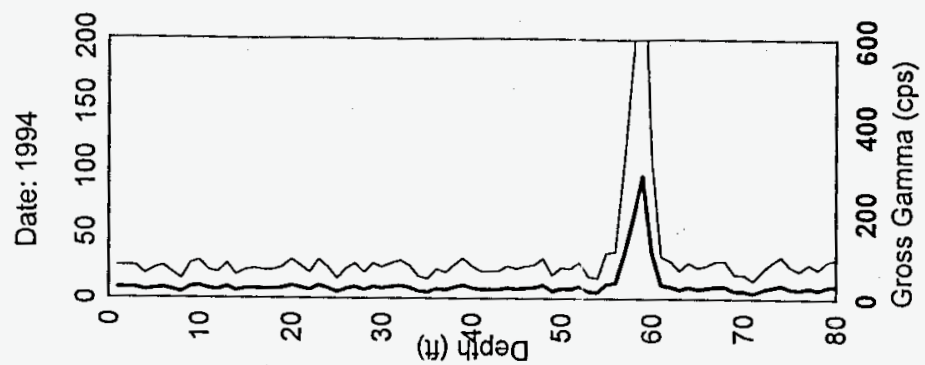

(sdo) punos6yoeg
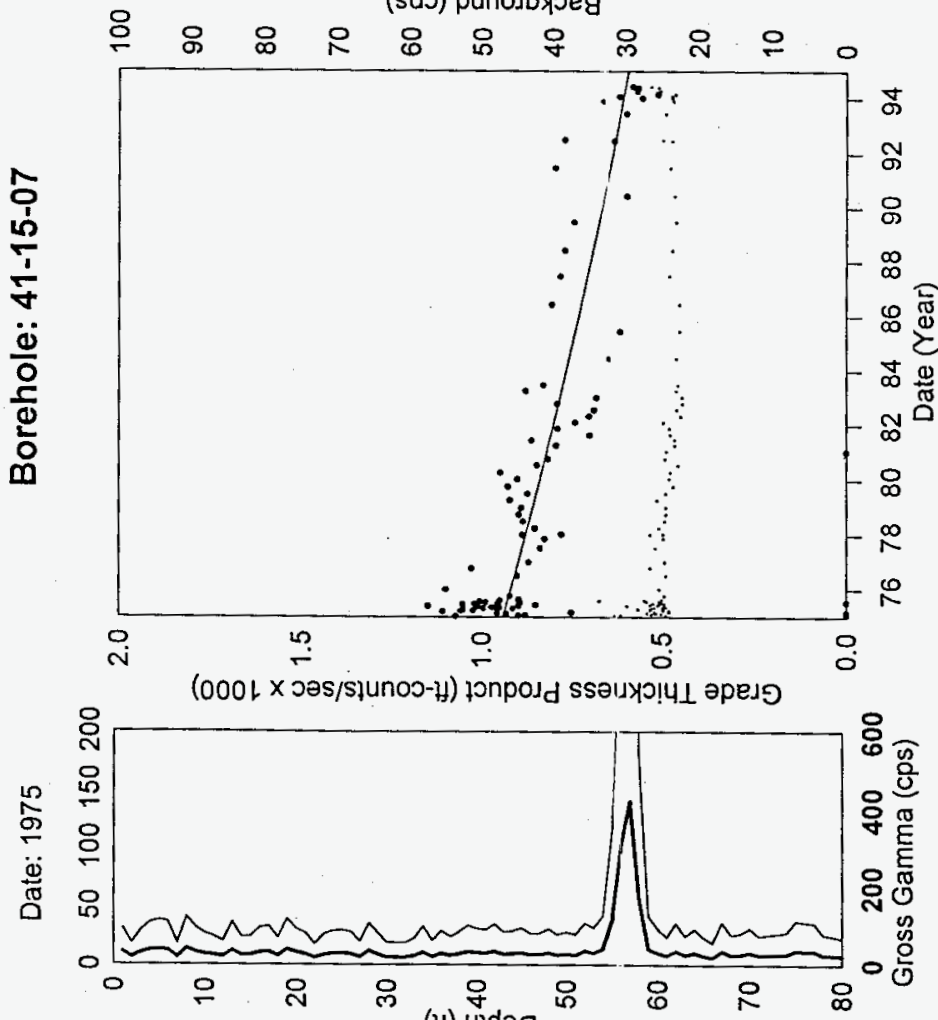

(4) 4 indəa 


\subsection{BOREHOLE 41-14-09}

Vadose zone monitoring borehole $41-14-09$ contains one interval of ${ }^{137} \mathrm{Cs}$ contamination at $19 \mathrm{~m}$ $(62 \mathrm{ft})$, as identified from the HPGe survey, Figure 2 . The activity measured by the surveillance logs had never exceeded $200 \mathrm{cps}$ and had never been reported as a UO.

The ${ }^{137} \mathrm{Cs}$ decay line plotted with the grade thickness product indicates that the contamination plume at $18.9(62 \mathrm{ft})$, while low in concentrations, is stable and is decaying in place.

These first two analyses demonstrate that the Dry Well surveillauce logs can identify stable contamination plumes that are not moving and are decaying in place. A reduction of error (variance) may be possible with further work.

\subsection{BOREHOLE 41-07-08}

Borehole 41-07-08 contains one interval of ${ }^{137} \mathrm{Cs}$ contamination at $18 \mathrm{~m}(59 \mathrm{ft})$, by HPGe survey, Figure 3. The activity measured by the Dry Well surveiliance logs has shown that the contamination level was continuously increasing from 1976 through at least 1986 . Three UO reports have been written about this vadose zone monitoring borehole.

Occurrence Report 76-119 on August 31,1976 , had indicated that the measured gamma-ray activity at

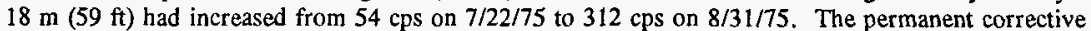
action was: "The leak volume appears well confined with mostly lateral movement. No corrective action indicated."

Occurrence report 76-163 on December 3,1976 , had reported a gradual increase in radiation that had doubled from $381 \mathrm{cps}$ on $10 / 5 / 76$ to $846 \mathrm{cps}$ on $11 / 30 / 76$. The permanent corrective action was: "the leak volume appears weil confined, but is exhibiting slow lateral movement. No corrective action indicated."

Occurrence report 77-34 on March 2, 1977, had reported "a gradual increase in radiation meeting the action criteria by a doubling of a radiation peak..." The measured activity at $18 \mathrm{~m}(59 \mathrm{ft})$ had increased from $732 \mathrm{cps}$ on $12 / 2 / 76$ to $1643 \mathrm{cps}$ on $3 / 2 / 77$. The permanent corrective action of this third Occurrence Report was: "the leak volume appears well confined, but is exhibiting slow lateral movement. No corrective action indicated."

The annual surveys between 1983 and 1993 are indicating poor repeatability. The use of different logging trucks, probes, and electronic instrument settings each year is probably the cause of most of the scatter. Preliminary evaluation of other boreholes with annual surveys have similar scatter, which may correlate. Plans are to examine the log surveys for a correlation. If a correlation can be established for a day when multiple boreholes were logged with the same equipment then a correction can be applied.

The radiation levels in this borehole had continued to increase until 1986. The maximum activity at $18 \mathrm{~m}(59 \mathrm{ft})$ was $63,450 \mathrm{cps}$.

The surveillance logs since 1988 (especially since 1992) are showirg a decrease in the netcontamination activity and the rate of decrease appears to be greater than the decay rate of ${ }^{137} \mathrm{Cs}$. 
Figure 2. Analysis of Surveillance Logs from Borehole 41-14-09.
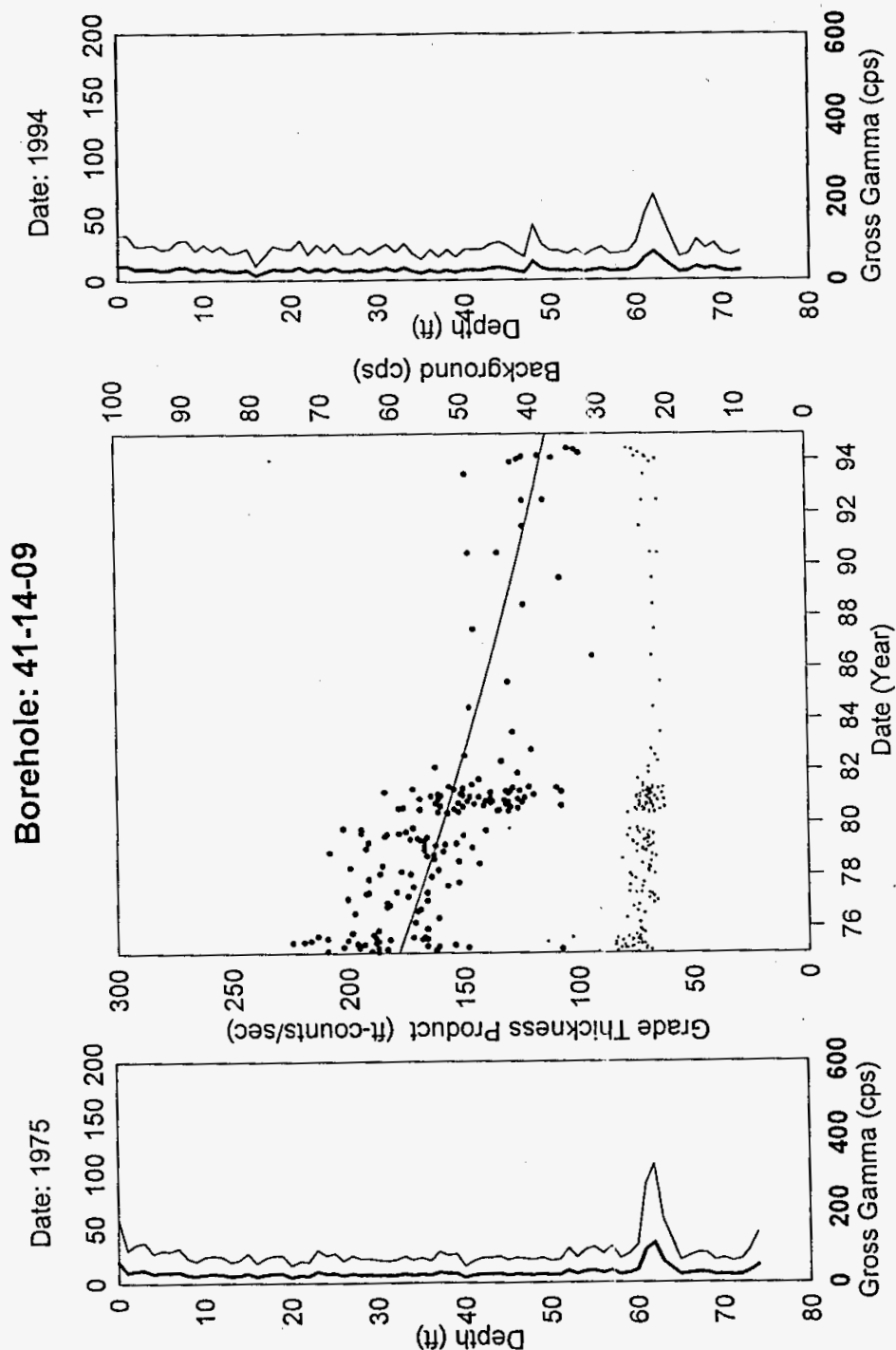
Figure 3. Analysis of Surveillance Logs from Borehole 41-07-08.
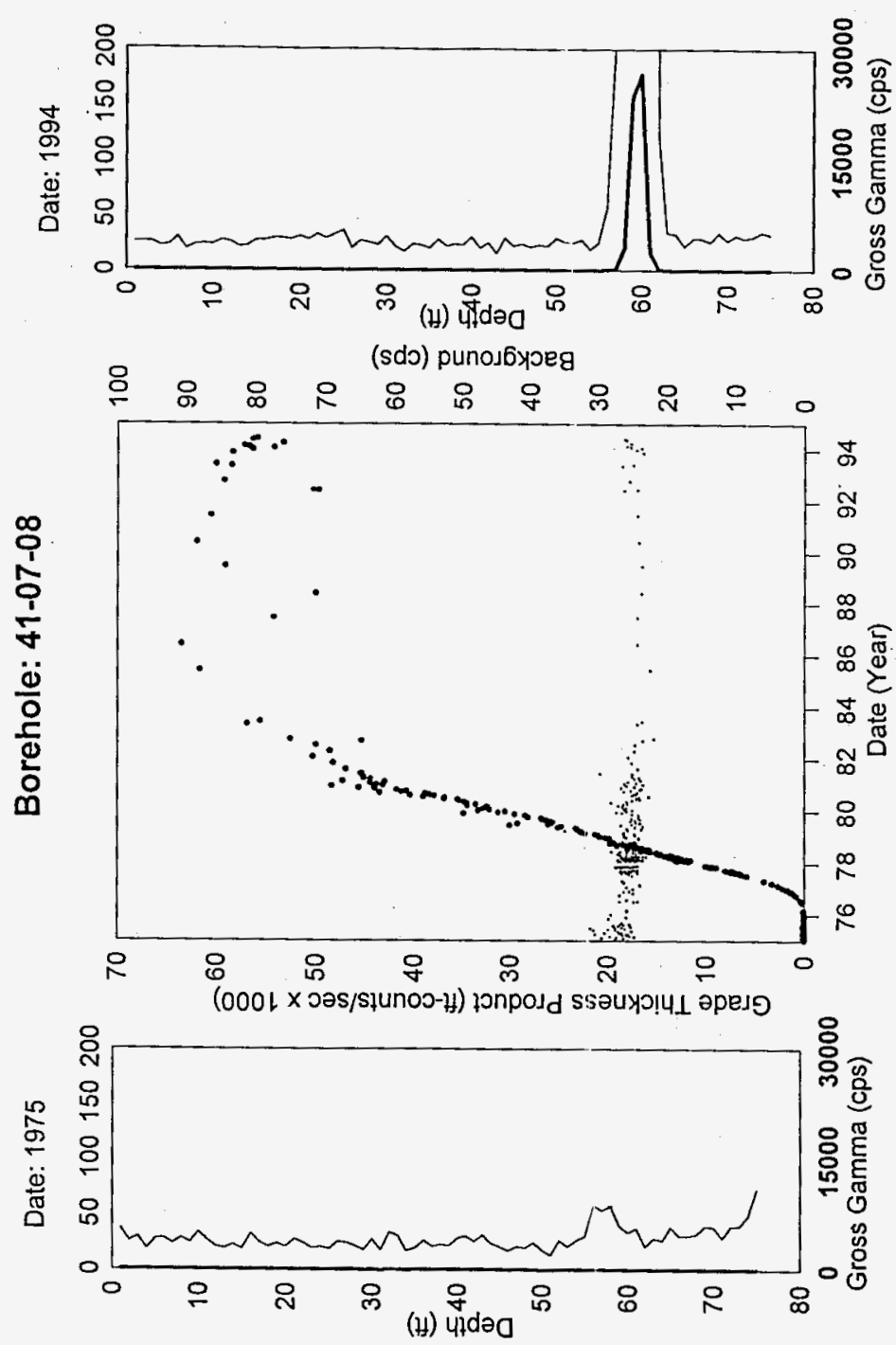
WHC-SD-ENV-TI-001, Rev. 0

The conclusion is that borehole 41-07-08 has shown a long-term and dynamic change in activity level with a significant increase from 1976 through 1986. The decrease that has been occurring since 1992 can not be completely explained as radioactive decay; continued monitoring should be performed at least quarterly (every 3 months).

\subsection{BOREHOLE 41-00-08}

Borebole 41-00-08 has two intervals of ${ }^{137} \mathrm{Cs}$ contamination (i.e., 19.5 and $22.6 \mathrm{~m}$ [64 and $74 \mathrm{ft}$ ]). The borehole, Figure 4, has been sealed with cement grout, which accounts for the elevated background activity. The 1975 survey $\log$ shows only one contamination interval at $22.6 \mathrm{~m}(74 \mathrm{ft})$. While the 1993 survey shows two contamination intervals, the new interval is located at 19.5 (64 ft). The activity at $22.6 \mathrm{~m}(74 \mathrm{ft})$ that was measured by the Dry Well surveillance logs is stable and is decaying in place.

The new contaminant interval at $19.5 \mathrm{~m}(64 \mathrm{ft})$ in 41-00-08 has a maximum peak activity of about $200 \mathrm{cps}$, but has been increasing steadily since about 1984 . The surveys since 1992 may indicate that this contaminaiton is becoming stable because the rate of increase apparently is decreasing.

The conclusion is that borehole 41-00-08 has shown an active contamination interval that should be monitored at least quarterly until stability can be demonstrated.

\subsection{BOREHOLE 41-11-10}

Vadose zone monitoring of borehole 41-11-10 identifies three zones of ${ }^{137} \mathrm{Cs}$ contamination, Figure 5. The moderate sensitivity logs obtained using the Green-GM (Geiger-Mueller) probe from Dry Well surveillance logs are analyzed for this borehole. The 1979 survey shows two contamination intervals. The highest activity interval occurs at $20.7 \mathrm{~m}(68 \mathrm{ft})$ and a low activity interval at $23.5 \mathrm{~m}(77 \mathrm{ft})$.

The grade thickness product of the contamination plume at $23.5 \mathrm{~m}(77 \mathrm{ft})$ indicates that the ${ }^{137} \mathrm{Cs}$ is stable and decaying in place. The peak at $23.5 \mathrm{~m}(77 \mathrm{ft})$ is plotteal on a scale of $200 \mathrm{cps}$. However, the grade thickness product for the dominant contamination plume at $20.7 \mathrm{~m}(68 \mathrm{ft})$ does not fit the ${ }^{139} \mathrm{Cs}$ decay line, indicating that some small amount of contaminant is being introduced. The plot scale at $20.7 \mathrm{~m}$ ( $68 \mathrm{ft}$ ) is 0 to $60,000 \mathrm{cps}$. The average background activity is not included on the plot, however, the background activity supports the position that the change is not from a system change.

The 1994 survey identified a third zone of the contamination at $25 \mathrm{~m}(82 \mathrm{ft})$ that is now the second highest concentration of ${ }^{137} \mathrm{Cs}$ in this monitoring borehole. The plot of the grade thickness product indicates that 1984 was the year when the contaminant was first detected at the borehole. The rate of change since 1993 appears to be accelerating. The increase in contamination at $25 \mathrm{~m}(82 \mathrm{ft})$ is not coming down the borehole from $20.7 \mathrm{~m}(68 \mathrm{ft})$ or from $23.5 \mathrm{~m}(77 \mathrm{ft})$. The contamination is from lateral movement.

The conclusion is that borehole 41-11-10 has a zone of rapidly increasing activity and must be monitored at least quarterly. 
Figure 4. Analysis of Surveillance Logs from Borehole 41-00-08.

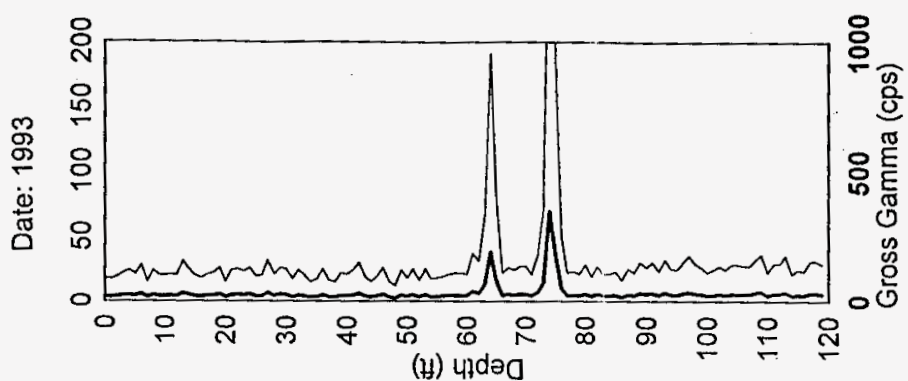

\section{$\therefore \quad$ (sdo) punosbyjoeg}
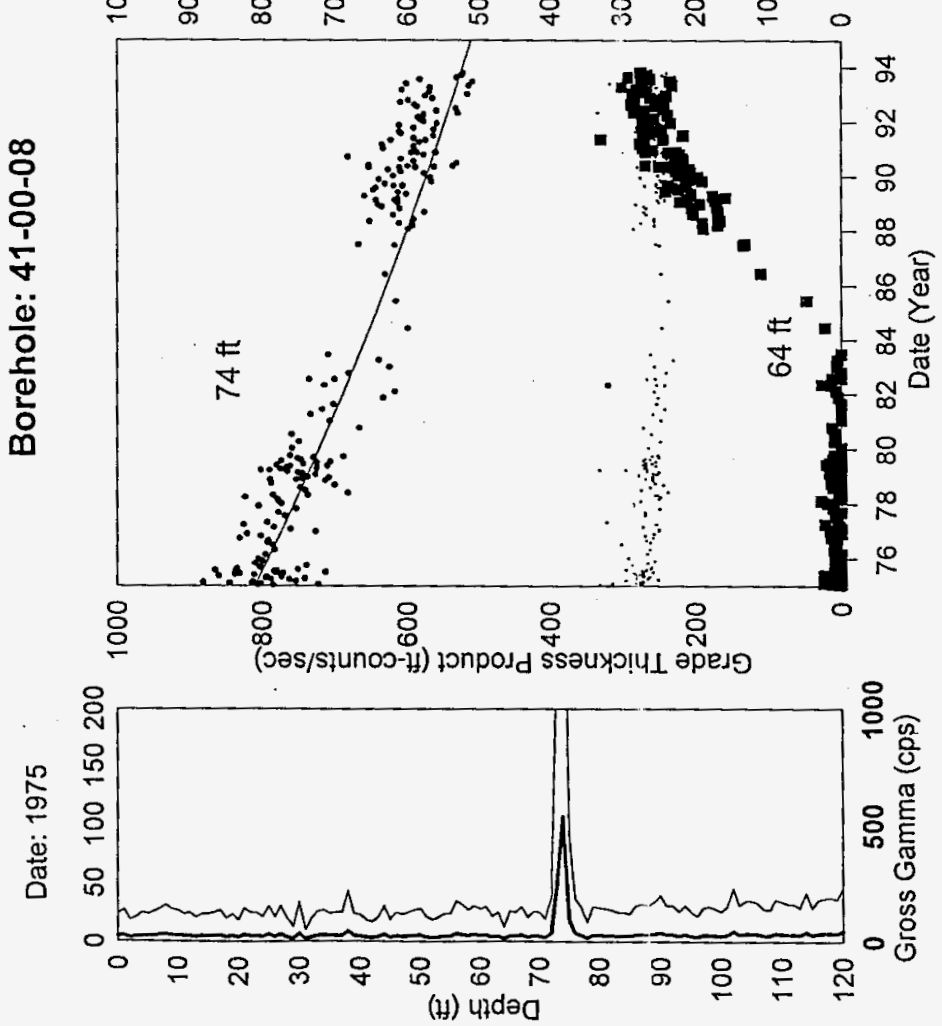
WHC-SD-ENV-TI-001, Rev. 0

Figure 5. Analysis of Surveillance Logs frorn Borehole 41-11-10.
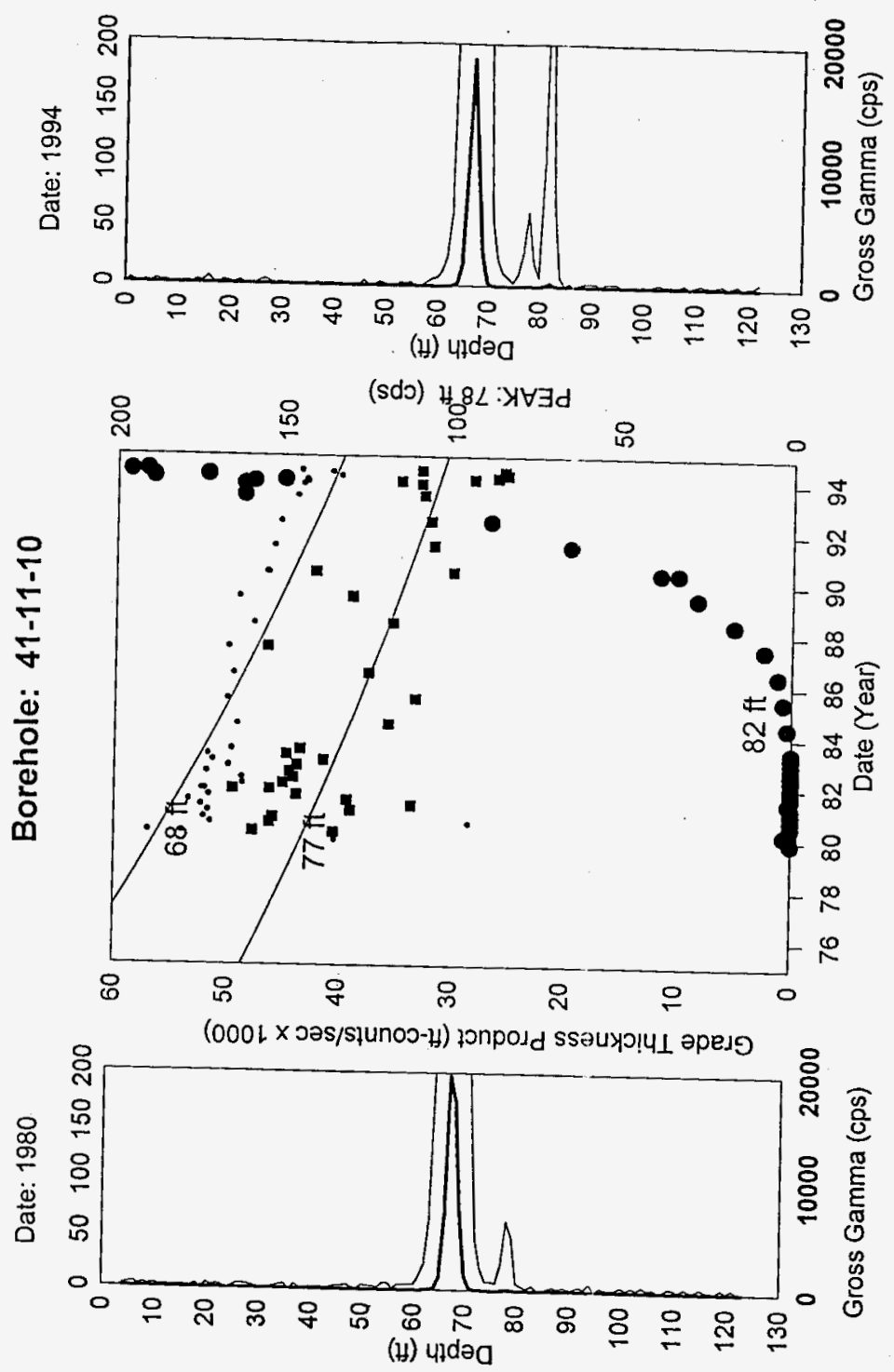
WHC-SD-ENV-TI-001, Rev. 0

\subsection{BOREHOLE 41-09-09}

Borehole 41-09-09 was identified in DOE 1995b with an active contaminant zone, Figure 6. There was one zone of contamination at $19.5 \mathrm{~m}(64 \mathrm{ft})$ in 1975 . The 1994 survey log shows a very high contamination zone at $22.6 \mathrm{~m}(74 \mathrm{ft})$. The activity that was recorded at $22.6 \mathrm{~m}$ (74 ft) of $80,000 \mathrm{cps}$ is the highest sodium-iodide count rate analyzed in this report.

The ${ }^{137} \mathrm{Cs}$ at $22.6 \mathrm{~m}$ (74 $\mathrm{ft}$ ) has been increasing since 1984. This is the third borehole that has identified 1984 as the year when a contamination plume was first identified. The rate of increase appears to be lower since 1990 . However, the change in the rate may be the result of electronic dead-time that has not been corrected.

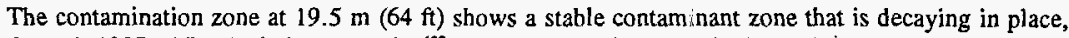
through 1987. The deviation from the ${ }^{137} \mathrm{Cs}$ decay line after 1987 is likely due to an increase in measured activity at $22.6 \mathrm{~m} \mathrm{(74} \mathrm{ft),} \mathrm{which} \mathrm{is} \mathrm{potentially} \mathrm{impacting} \mathrm{the} \mathrm{calculation} \mathrm{of} \mathrm{the} \mathrm{grade}$ thickness product by preventing the lower portion of the gamma-ray peak from returning to the background counting activity.

The conclusion is that borehole 41-09-09 has a zone of rapidly increasing activity that must be monitored at least quarterly.

\subsection{BOREHOLE 41-02-02}

Vadose zone monitoring borehole 41-02-02 has been monitored weekly since 1975, Figure 7. Between 1975 and 1982 one zone of contamination was identified by each of the Dry Well surveillance logs at $14.6 \mathrm{~m} \mathrm{(48} \mathrm{f})$. At the time of this report, the surveys between 1982 and 1984 have not been converted successfully to the new computer format, creating a data gap. The surveys from 1984 through 1995 show the contamination at two intervals instead of one, 14.6 and $15.5 \mathrm{~m}$ (48 and $51 \mathrm{ft}$ ). During the data gap interval, the contamination plume had changed from a single peak to a double peak.

The plot of the grade thickness product indicates that the ${ }^{137} \mathrm{Cs}$ plume is not stable and has been slowly increasing, even though the maximum measured activity is less than $200 \mathrm{cps}$ and no UO report has been issued. The surveillance logs since 1993 have been decreasing, and may be indicating a change in the subsurface conditions.

The conclusion is that borehole 41-02-02 should be monitored quarterly to establish the condition of the vadose zone contamination. If the contamination is stable and is not moving, the monitoring can be decreased to annual. 
WHC-SD-ENV-TI-001, Rev. 0

Figure 6. Analysis of Surveillance Logs from Borehole 41-09-09.

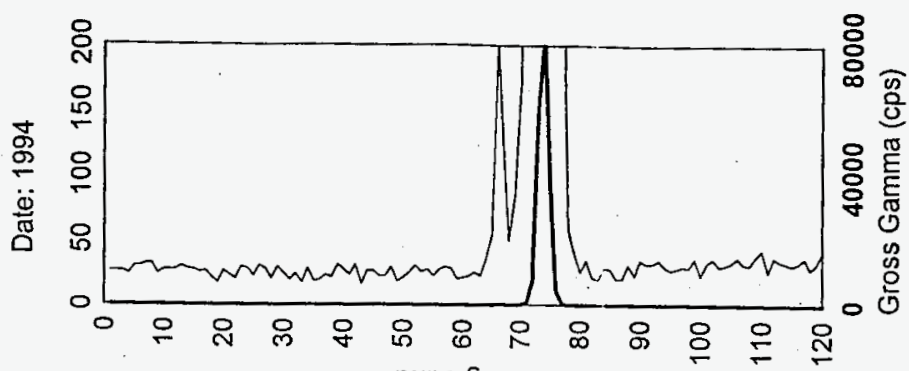

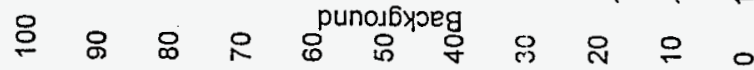
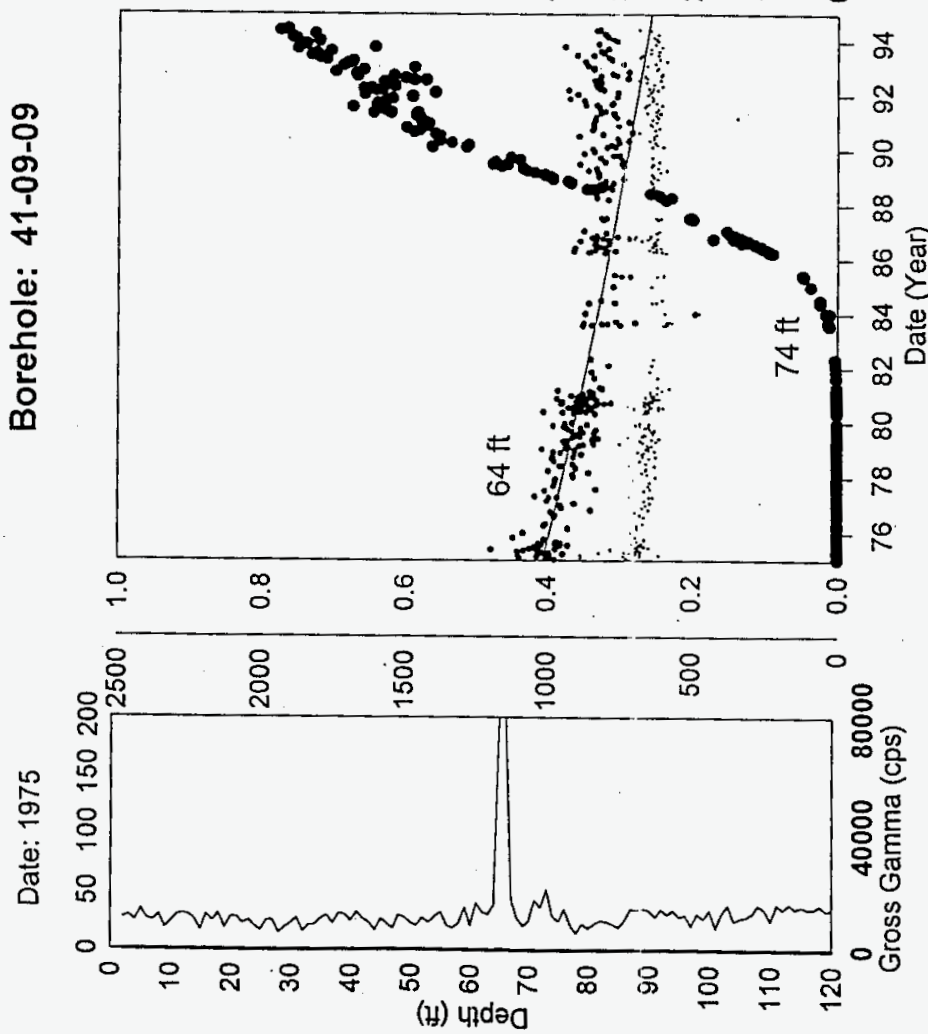
WHC-SD-ENV-TI-001, Rev. 0

Figure 7. Analysis of Surveillance Logs from Borehole 41-02-02.

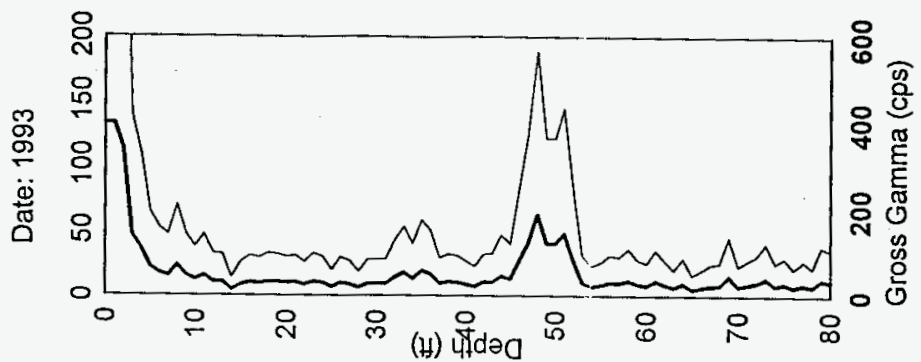

(sdo) punos6yoeg

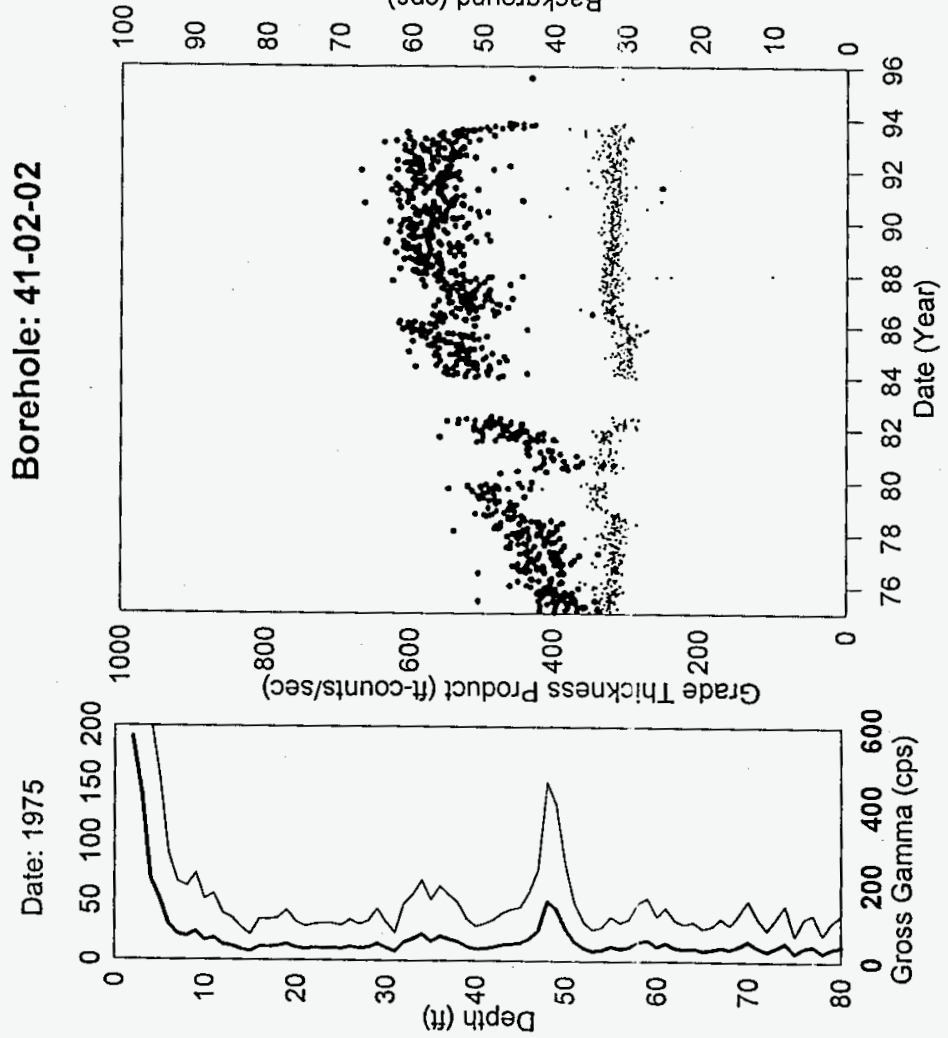




\subsection{BOREHOLE 41-10-01}

Borehole 41-10-01 contains one zone of ${ }^{137} \mathrm{Cs}$ contamination at $20.7(68 \mathrm{ft})$ with low concentrations, Figure 8. The Dry Well surveillance logs have remained well below the $200 \mathrm{cps}$ action level. The grade thickness product of the 254 surveys indicates that a possible increase in activity level has been occurring since 1984. The statistical uncertainty of the measured activity is high, however, the increasing trend is outside of 1 sigma, but less than 2 sigma.

Evidence of contaminant movement is subject to further study. Therefore, it is recommended that borehole 41-10-01 should be monitored quarterly to establish the condition in the vadose zone. If the contamination is stable and not moving the monitoring can be decreased to annual.

\subsection{BOREHOLE 41-04-03}

Vadose zone monitoring borehole 4l-04-03 contains one zone of high gamma-ray activity at $6.1 \mathrm{~m}$ $(20 \mathrm{ft})$, Figure 9 . The high gamma-ray activity is from pipeline(s) that are relatively close and were used to transport waste to the underground storage tanks. The borehole surveys between 1975 and 1995 are unusual for a pipeline because they are showing a continuous decrease, not erratic changes as would be expected from a pipe that carries high-level radioactive waste. However, the tanks have received no waste since the 1960 's.

There is an 18 month gap in the historical survey data that has not been located on the archival storage tapes. The high survey frequency overflowed the data base before the data was archived.

Because of the unusual rate of decrease in the historic surveys the data is presented in this report. There is a significant decrease from 3600 to $1200 \mathrm{cps}$ of the computed grade thickness product from the Dry Well surveillance logs between 1975 and 1995 . The rate of decrease is about $200 \%$ greater than what can be explained as the decay of ${ }^{137} \mathrm{Cs}$. The ${ }^{137} \mathrm{Cs}$ decay line is not plotted.

The HPGe survey (DOE 1995a) of this borehole had measured three anthropogenic radionuclides at low concentration levels. The radionuclides and approximate concentration levels are: ${ }^{137} \mathrm{Cs}$ at 5 $\mathrm{pCi} / \mathrm{g},{ }^{154} \mathrm{Eu}$ at $2.7 \mathrm{pCi} / \mathrm{g}$, and ${ }^{60} \mathrm{Co}$ at $0.3 \mathrm{pCi} / \mathrm{g}$.

The change with time of the grade thickness product of the Dry Well surveillance logs between 1975 and 1995 was evaluated by an outside expert (Appendix D). The uutside expert was not told that the contamination zone was from a pipeline.

The stability of the instrumentation was evaluated for systematic and random errors. A root mean square of consecutive surveys was calculated and analyzed for validity. A decay projection, consistent with the measured radionuclides, was fit to the decreasing peak area.

The conclusion of the analysis of the 41-04-03 Dry Well surveillance logs was that there are strong indications that some portion of the radionuclides are moving. It is recommended that borehole 4104-03 should be monitored quarterly. 
WHC-SD-ENV-TI-001, Rev. 0

Figure 8, Analysis of Surveillance Logs from Borehole 41-10-01.

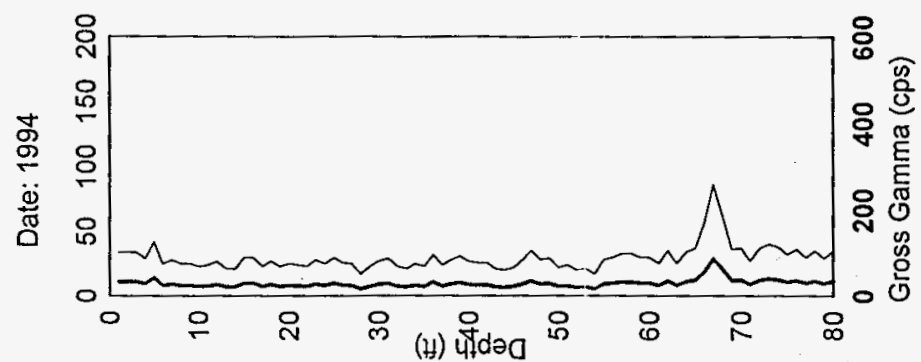

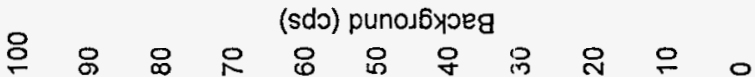

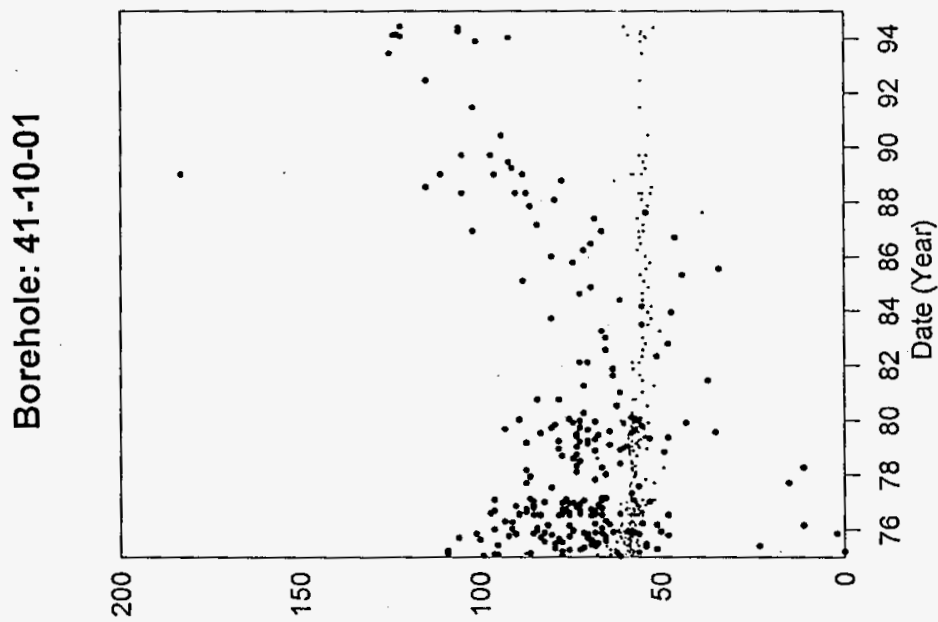

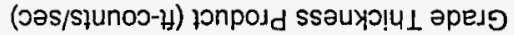

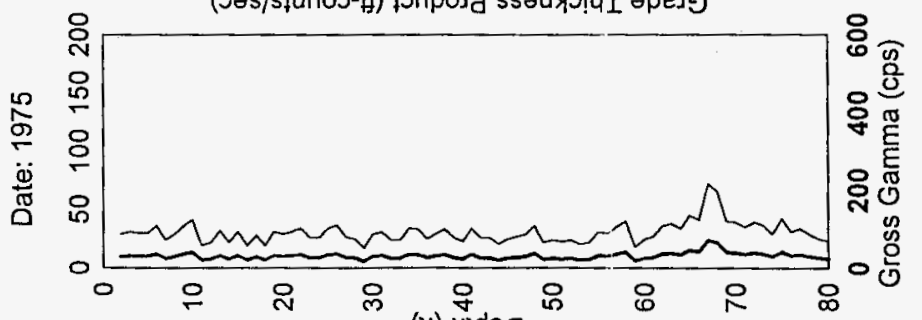

(H) पidoa 
WHC-SD-ENV-TI-001, Rev. 0

Figure 9. Analysis of Surveillance Logs from Borehole 41-04-03.
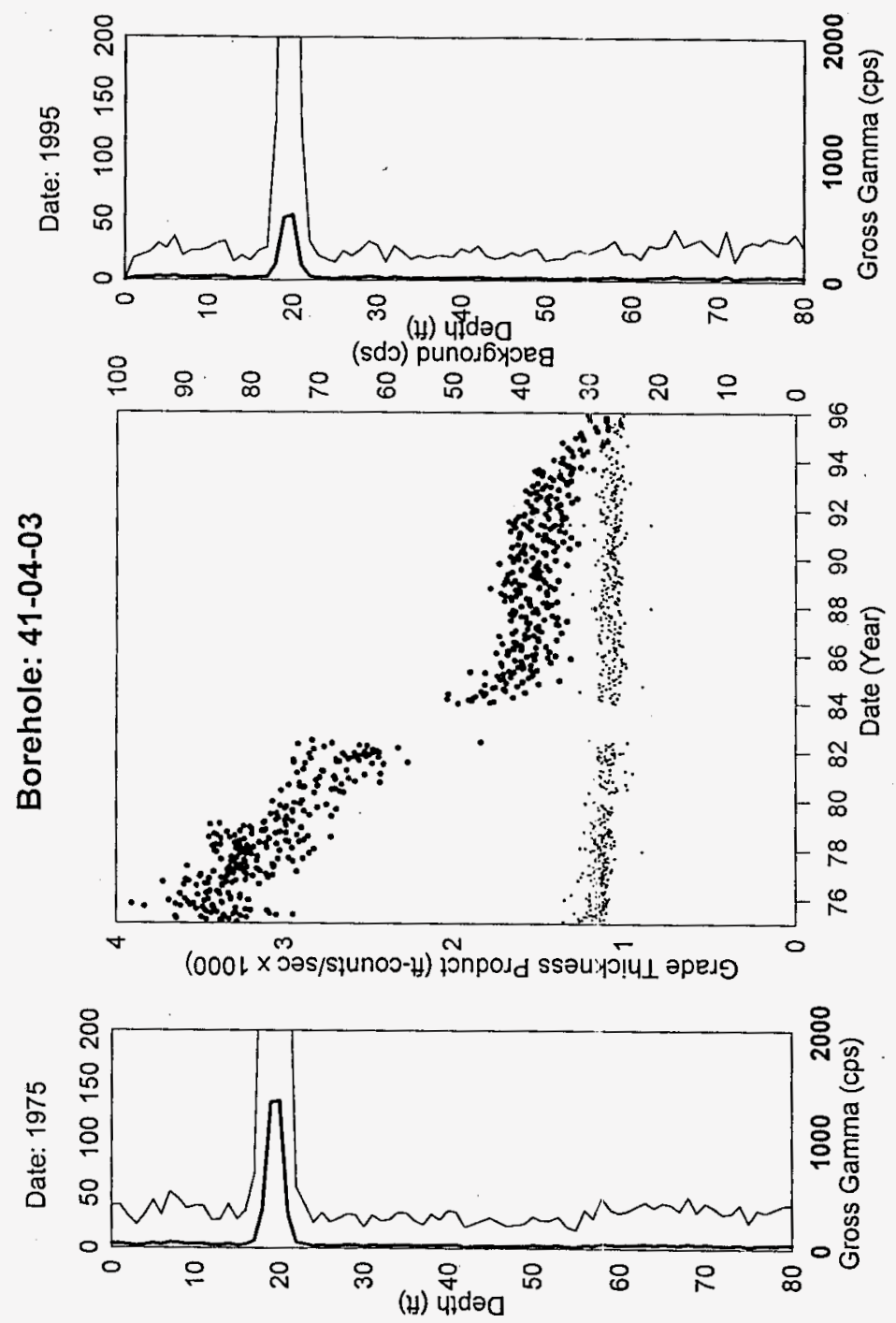


\subsection{BOREHOLE 41-10-08}

Vadose zone monitoring borehole 41-10-08, Figure 10, was identified in an occurrence report (75-04 on 1/7/75) with "a rise in radiation levels at the 16.2 to $17.4 \mathrm{~m}$ (53 to 57) foot depth." The peak readings shown in the occurrence report bad indicated that the activity increased rapidly from 53 cps on $9 / 25 / 74$ to a maximum of 328 cps on $11 / 26 / 74$. Between the maximum reading and the date of the occurrence report, several weekly surveys showed an apparent decrease in peak activity.

This borehole was selected for analysis based on the occurrence report.

The rate of decrease in the grade thickness product during 1975 had indicated that the radionuclide was characteristic of the 368-day half life of ${ }^{106} \mathrm{Ru}$. However, the rate of change had appeared to be accelerated during 1976, prompting concern. The change at $16.6 \mathrm{~m}$ (54 ft) in borehole 41-10-08 was evaluated by an outside expert (Appendix E).

The evaluation (Figure 11) confirmed that the decrease in measured activity for the 12 months of 1975 was from radioactive decay of ${ }^{106} \mathrm{Ru}$. However, during the tirst half of 1976 the activity consistently had decreased, by a factor of $75 \%$, which is much faster than radioactive decay. After the abrupt decline in 1976 , the rate of decrease again had returned to the 368 day half-life of ${ }^{106} \mathrm{Ru}$. The high logging frequency made it possible to capture the rapid changes that were occurring in the subsurface. An annual survey would have missed this event.

The conclusion is that between October and December of 1974 the leading edge of a contamination plume containing ${ }^{106} \mathrm{Ru}$ intersected borehole $41-10-08$ between 15.2 and $18.3 \mathrm{~m}$ ( 50 and $60 \mathrm{ft}$ ). The concentration of ${ }^{106} \mathrm{Ru}$ in the plume was constant as it migrated past the borehole and the radioactive decay was observed. Then, between January and June of 1976 , the trailing edge of the plume migrated beyond the monitoring range of the borehole. The residual radionuclide present in the formation (after June 1976) from the plume had continued to decay to non-detectable levels.

The radioactive plume that intersected this borehole was moving laterally and not vertically through the formation at this location. 
WHC-SD-ENV-TI-001, Rev. 0

Figure 10. Analysis of Surveillance Logs from Borehole 41-10-08.

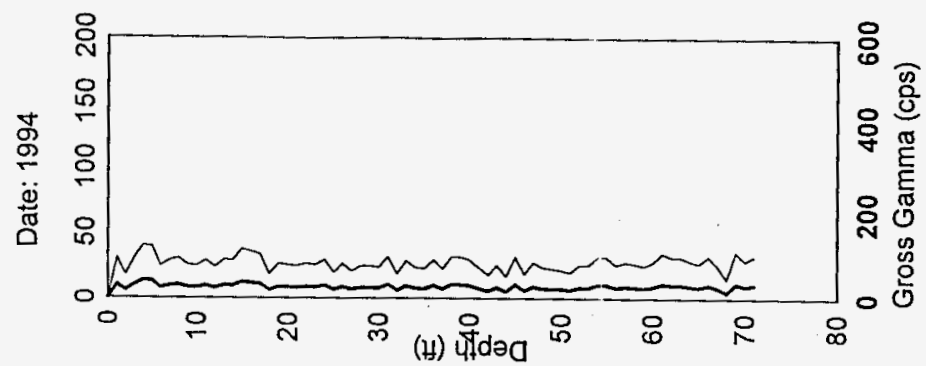

(sdo) punos6yog

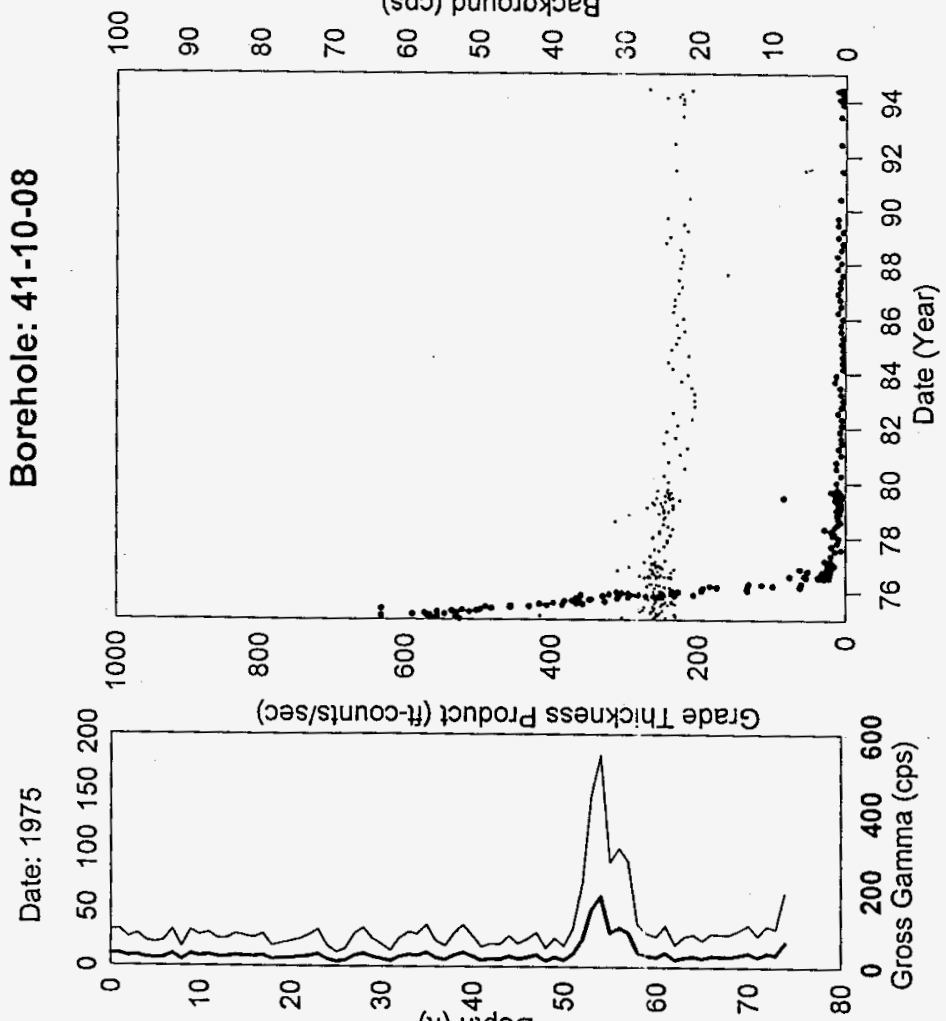

(H) uldea 


\section{SX Tank Farm Dry Well 110-08}
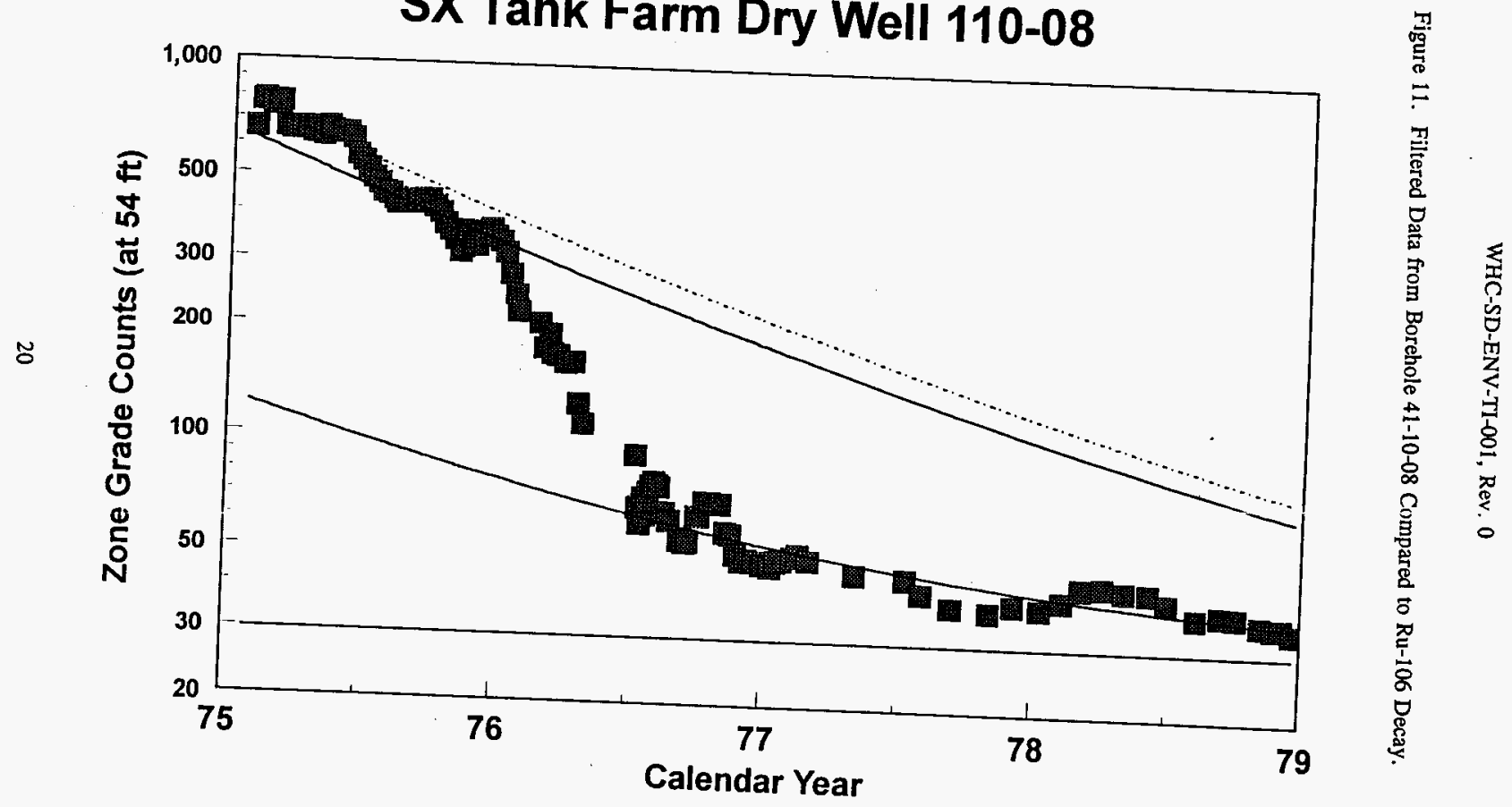
WHC-SD-ENV-TI-001, Rev. 0

\subsection{CONCLUSIONS AND RECOMMENDATIONS}

Three conclusions of the Tank Farms Dry Well surveillance logs evaluation are as follows:

- Historical Tank Farms surveillance logs are useful. Activities to convert the log data from the obsolete computer format to a current architecture are justifiable.

- Changes in borehole gamma-ray intensities in the vadose zone around the SX Tank Farms do exist and continued borehole geophysical monitoring is necessary.

- The geologic strata around the Tank Farms are influencing contaminant transport and further review is necessary.

Two recommendations that derived from the Tank Farms Dry Well surveillance logs evaluation are as follows:

- The historic surveillance logs of all the single-shell Tank Farm boreholes should be reviewed for indications of dynamic radioactive plume conditions.

- The historic surveillance logs that were acquired prior to 1975 should be retrieved from storage for all Tank Farms wells that indicate dynamic subsurface conditions. They may assist in identifying the event or events that had introduced the contaminants in the vadose zone.

\subsection{REFERENCES}

DOE 1995a, Vadose Zone Characterization Project at the Hanford Tank Farms, Tank Summary Data Report for Tank SX-104, GIPO-HAN-3, prepared by Rust Geotech for the Grand Junction Projects Office, Grand Junction, Colorado, September

DOE, 1995b, Vadose Zone Characterization Project at the Hanford Tank Farms, Tank Summary Data Report for Tank SX-109, GJPO-HAN-11, prepared by Rust Geotech for the Grand Junction Projects Office, Grand Junction, Colorado, November

DOE, 1996, GJPO-HAN-4, Vadose Zone Characterization Project at the Hanford Site, SX Tank Farm Report - Final Draft, July 1996, prepared by Rust Geotech for the Grand Junction Projects Office, Grand Junction, Colorado. 
WHC-SD-ENV-TI-001, Rev. 0

This page intentionally left blank. 


\section{APPENDIX A}

\section{TANK FARM DRY WELL SURVEILLANCE LOGGING PROGRAM SUMMARY}

The Dry Well surveillance logging activity for detecting leaks from the single-shell underground storage tanks began operation in 1975 . The monitoring program is summarized in Table A-1.

\begin{tabular}{|c|c|}
\hline Number of Tank Farms & 12 \\
\hline $\begin{array}{l}\text { Total number of single-shell } \\
\text { tanks }\end{array}$ & 149 \\
\hline $\begin{array}{l}\text { Number of monitoring } \\
\text { boreholes (Dry Wells) }\end{array}$ & 780 арpх \\
\hline Monitoring frequency & $\begin{array}{l}\text { varied from weekly to annually; depended on tank status and } \\
\text { monitoring requirements }\end{array}$ \\
\hline Number of monitoring trucks & $\begin{array}{ll}1975-1981 & \begin{array}{l}\text { (pickup truck units, manual operation, output to } \\
\text { punched paper tape) }\end{array} \\
\text { 1981-1995 } & \text { (5 logging vans with computer control) }\end{array}$ \\
\hline Monitoring probe types used & $\begin{array}{ll}1 \text { - } & \text { Red Geiger-Mueller (heavily shielded) Gross Gamma } \\
\text { (Very High Gamma) } \\
2 \text { - }\end{array}$ \\
\hline Logging Speed & $13.7 \mathrm{~m} \mathrm{(45} \mathrm{ft)}$ per minute \\
\hline Sample Interval & $30 \mathrm{~cm}$ (1 foot) \\
\hline Logging Sample Time & 1 second per sample interval \\
\hline Borehole Identification & $\begin{array}{l}\text { Borehole identification entered as } 6 \text { digit number on thumb } \\
\text { wheels. (Tank Farm, Tank, Hols Location) }\end{array}$ \\
\hline Equipment Identification & $\begin{array}{l}\text { Probe type entered as } 2 \text { digit nurnber on thumb wheels. Truck } \\
\text { number and probe serial number not recorded. }\end{array}$ \\
\hline $\begin{array}{l}\text { Down-hole detector } \\
\text { electronics, } \\
\text { Logging cable, and } \\
\text { Truck mounted electronics }\end{array}$ & $\begin{array}{l}\text { - Electrical power to the down-hole detector assembly was } \\
\text { supplied through the single conductor logging cable. } \\
\text { The detector pulses were transmitted back up the logging } \\
\text { cable by capacitance coupling. } \\
\text { The truck mounted electronics analog style. Counts } \\
\text { analog pulses from detector for input to micro-computer }\end{array}$ \\
\hline
\end{tabular}




\begin{tabular}{|c|c|c|}
\hline Electronics Adjustments & & $\begin{array}{l}\text { The truck mounted electronics was adjusted each time the } \\
\text { logging probe was changed or repaired. } \\
\text { Adjustments were made to the amplifier gain and lower } \\
\text { level discriminator to provide optimum discrimination } \\
\text { between electronic noise and detector signal pulses. }\end{array}$ \\
\hline $\begin{array}{l}\text { Log Acquisition Program } \\
\text { logic (generalized) }\end{array}$ & & $\begin{array}{l}\text { Operator enters Borehole ID by thumb wheels. } \\
\text { Operator enters Probe Type by thumb wheels. } \\
\text { Program retrieves max imum survey depth, logging speed, } \\
\text { sample increment from internal table. } \\
\text { Operator positions probe adjacent to borehole, to zero the } \\
\text { survey depth and sends signal to computer. } \\
\text { Operator positions probe over borehole to be logged and } \\
\text { sends signal to computer. } \\
\text { Computer program lowers probe to specified depth, starts } \\
\text { winch motor to retrieve: probe at constant rate, starts } \\
\text { detector counter then begins acquisition loop. } \\
\text { When depth increment crossed the program: (stops } \\
\text { detector counter, reads the counts, stores counts in } \\
\text { temporary memory area, clears the counter, restart the } \\
\text { detector counter, reset the depth increment, and return to } \\
\text { the program loop to wait for the next depth increment). } \\
\text { At end of survey, data is stored for later transfer to } \\
\text { analysis data base. }\end{array}$ \\
\hline Corrections & & $\begin{array}{l}\text { Electronics selected to rninimize detector dead-time. No } \\
\text { corrections for pulse pile-up or electronics dead-time are } \\
\text { applied. } \\
\text { Depth coefficient verified daily by lowering probe into } \\
\text { the specified horehole of known depth until cable tension } \\
\text { switch toggled. Error of less than I percent required to } \\
\text { pass. Difference between actual and truck measured } \\
\text { depth are not applied to the log surveys acquired for that } \\
\text { day. }\end{array}$ \\
\hline
\end{tabular}




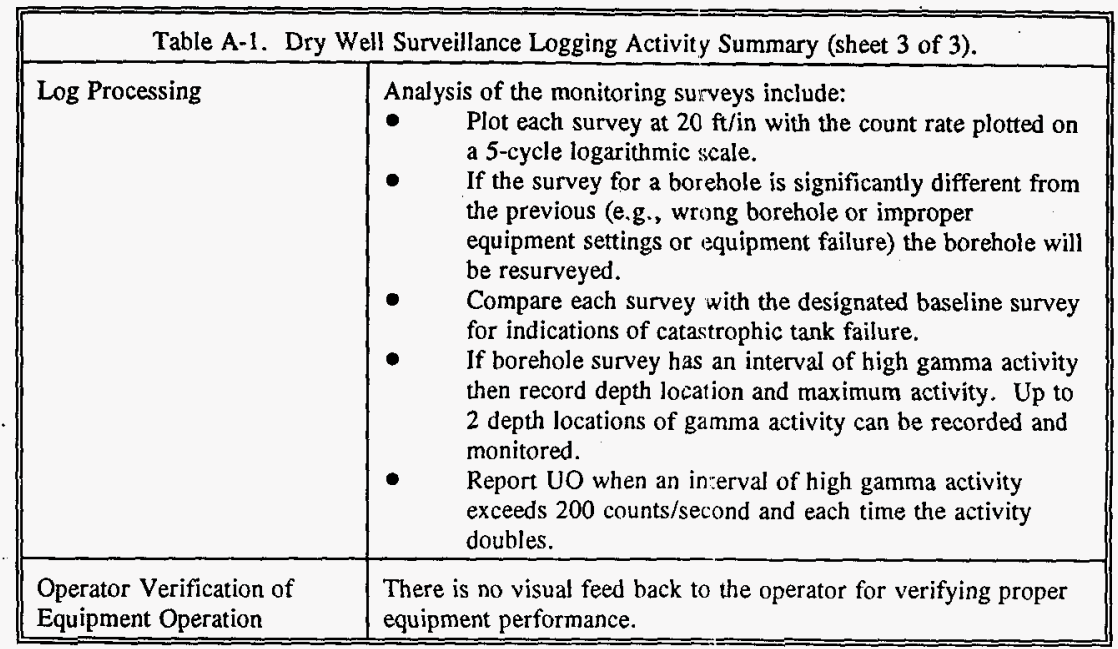

Processing the Dry Well survey logs can not be completely automated and requires an integration of manual (human judgement) and computer analysis. The most frequent problems are:

- The gamma activity an individual survey depth location is occasionally -1 or 0 , which is considered as a data gap. The data gaps are not limited to background intervals and can occur within contamination intervals. The data gaps can not be ignored, especially within a contamination interval. The frequency of data gaps requires that a substitution value be provided.

- Depth errors between successive monitoring surveys can be identified in boreholes containing contamination intervals. The apparent depth of the maximum counting activity can vary by plus and minus $4 \mathrm{ft}$. In boreholes with multiple zones of contamination, the range (spread) between the computed gamma activity of successive logs cin be minimized (improve precision) if the log surveys are normalized to a common depth and a fixed calculation window is used.

Significant depth errors are anticipated prior to 1986 . Between 1981 and 1986 automated depth control was developed and refined. 
Several possible causes of the depth errors include the following:

- There were multiple logging trucks with potentially different settings/adjustments to the cable and winch, and different amounts of lubrication. It is likely that the depth system on each truck would record less or more cable into the hole on a routine basis.

- Dirt in the optical encoder (depth measuring device) can cause sporadic errors.

- The encoder signal to noise level may cause erratic counting in field conditions or with temperature changes.

- An early depth trigger (tension switch toggle) can be created by the logging cable dragging across the top of casing when going into the hole to the bottom of the hole.

- A late depth trigger can be created by the cable spiraling around inside the hole after the tool touches bottom and the weight sensitivity switch is set too low. 


\section{APPENDIX B}

\section{CONSIDERATIONS OF GEOPHYSICAL LOGGING EQUIPMENT AND ANALYSIS}

Development and operation of borehole geophysical logging equipment and analysis of the measurement data requires integration of several scientific disciplines. The first in situ borehole geophysical measurement instrumentation was developed about 50 years ago and has evolved into a wide array of detector types (not just gamma-ray detectors). Gexphysical logging has proven invaluable in some applications (such as petroleum and mineral exploration) where the equipment has been designed and optimized for each specific environment and to the geophysical variables most amenable to measurement.

Use of borehole geophysical measurement instruments has not been universally accepted for every application for several reasons. The reasons for limited acceptance range from nonmeasurable properties, elevated detection thresholds, improper detector configurations, and cost. Adding to the guarded acceptance of borehole geophysical measurements is the constant presence of the "Murphy Principle: If anything can go wrong, IT WILL!". There are countless instances where people with good intentions have attempted to quickly make geophysical measurements only to find, after complete failure, that their design assumptions were opposite to the actual conditions (assuming there was an opportunity to investigate further). In many of these instances, the failed activity hindered future involvement of subsurface geophysics far more than no measurement at all.

A summary of the considerations of geophysical logging equipmert and analysis is presented to show the complexity and potential pit-falls. This summary does not include all of the gamma-ray detector types and data interpretation considerations. The items of consideration demonstrate the difficulty of acquiring accurate and repeatable measurements.

Unfortunately, failures can occur even when all the considerations are addressed and the response from the equipment is repeatable. It is possible that the data are invalid because of unidentified variables or improperly defined characterization studies.

Fortunately, with proper diligence to equipment calibration and investigation of the subsurface conditions, it has been shown that valid, accurate, and precise geophysical measurements can be acquired.

\section{DETECTOR FAILURE}

Sodium-iodide is the best scintillation (light emitting) type of the gamma-ray detectors and was used to acquire the majority of the leak detection log surveys in the Tank Farms. The detector can be connected to electronics for collecting both spectral and gross gamma activity. These detectors are subject to several type of failures, both catastrophic and progressive with time. Six kinds of detector failure are discussed:

- The crystal is hygroscopic. If the hermetic seal is lost the crystal will absorb moisture from the air and be transformed into powder in a relatively short time. Loss of the detector signal is gradual during this transformation. 
- The crystals are subject to fogging or yellowing from natural aging, which will generally occur within a few years. The loss of detector signal is gradual and may appear to be even slower (several years) if the detector is operated as a gross-gamma system.

- The optical coupling (special optical grease) between the detector and the photo multiplier tube can degrade with time from vaporization. Loss of the detector signal is gradual and may appear even slower if the detector is operated as a gross-gamma system.

- The crystals are subject to cracking from either percussion shock (dropping) or thermal shock (eg. lowering the detector into water in the winter time). The fractures are generally significant and cause substantial loss of count rate. This is the ideal type of failure where the loss of signal is instantaneous, significant, and indisputable.

- The crystals are subject to micro-fracturing that will cause loss of gamma-ray energy resolution, but may not significantly reduce the gross gamma counting activity. Loss of the detector signal may be gradual.

- The crystals will begin to self-scintillate when their temperature exceeds about $120^{\circ} \mathrm{F}$. This condition is generally temporary and does not necessarily permanently damage the crystal.

\section{DETECTOR ELECTRONICS}

Two electronic components are required at the sodium-iodide scintillation detector. One component (usually, a photo-multiplier tube) converts the detectors light pulses to an electrical voltage signal. The second component is a signal pre-amplifier. Frequent problerns with these components include:

- The photo-multiplier tube must be shielded against magnetic fields. If not properly shielded, the magnetic field fluctuations present within the steel casing in the borehole will cause significant signal gain changes.

- Detectors that are subject to very high rates of gamma-ray activity must have modified highvoltage power supplies to prevent signal loss in the high gamma-ray activity zones.

- The pre-amplifier must be matched with the input from the detector and output to the up-hole counting electronics. If gamma-ray spectra are being collected, the pre-amplifier must collect the full light output of detector to provide the best possible gamma-ray energy resolution. The pre-amplifier must not reduce the system count rate lirnit by stretching to the detector signal (i.e., increase the detectors dead-time). The pre-amplifier must be capable of driving the signal over the attached logging cable to the up-hole electronics without significant loss of counting capabilities.

\section{SYSTEM CALIBRATION}

The logging system must be characterized and calibrated as a unit to assure that the response is valid. Daily verification of equipment operation must be performed with the results compared to acceptance limits. 
System characterization must include:

- Identify the electronic signal to noise ratio and set the counting electronics (gain and threshold discriminator) to minimize conflicts.

- Identify whether the counting system is paralyzable or non-paralyzable at high gamma-ray counting activities (this will provide a double check on the electronics dead-time measurements).

- Measure the electronics and detector dead-time and either set a maximum count rate limit or define a correction curve.

- If pulse pile-up rejection electronics are present then perform measurements to verify operation and the impact on the dead-time electronics.

The system calibration must be performed each time the equipment is repaired and when the equipment is unable to meet the limits of the daily verification checks. The calibration must also be performed at a frequency that is at least $1 / 4$-th of the "mean-time-before-failure" of the most vulnerable component (i.e., the sodium-iodide crystal).

Characterization and periodic calibration of the depth measurement system must also be performed.

\section{HANFORD BOREHOLE GEOPHYSICS CONCERNS}

Several borehole construction related problems have been identified at the Hanford Site. The presence of these problems must be identified when analyzing borthole geophysical logs. Failure to identify these problems can lead to in improper conclusion and create unwarranted concern, UO reporting, and special investigations.

Borehole related effects include:

- Movement of radioactive contaminants in the void space between the casing and formation. In recent past, liquid waste that was discharged to the subsurface had encountered unsealed wells and had traveled directly to the groundwater. Since untreated liquid discharges to the subsurface have been discontinued the potential for environmental impact has been significantly reduced.

Even though there is concern when active vertical movement is identified in the subsurface even in the void space behind the casing. There is substantially more concern when the movement is identified as wide-spread and within the formation, instead of movement that is localized along the borehole wall. 
- Radioactive contaminants from the surface have been washed into the borehole casing and have rapidly traveled to the bottom of the borehole. This is most common when the top of the borehole is flush with the ground surface and large amounts of water are released from rapidly melting snow.

Radioactive contaminants that were washed inside the casing will be smeared the full borehole length and may have their highest concentration at the bottom of the borehole. A swab of the borehole can generally identify this problem.

- Radioactive contaminants present in the formation when the borehole was being drilled have been transported to lower depths by the drilling process. In these cases the contamination will appear to be deeper than its actual location and may be interpreted incorrectly. 


\section{APPENDIX C}

\section{SOFTWARE PROGRAM FOR EXAMINING DRY WEIL SURVEILLANCE LOGS}

The software program "TFGROSS" was written to assist in analyzing the historical Dry Well surveillance logs. The program can be directed to identify and correct problems with the recorded data values, as discussed in Appendix A. The program options and input parameters are summarized below. Input parameters are saved for each borehole and can be changed each time the program is executed. The input parameters are presented on one screen form, an example is shown in Figure C-1.

\section{SURVEY FILE NAMES}

Each Dry Well survey is recorded as a separate file. The file name identifies the logging probe number $(01-14)$ and the survey date (yymmdd). Processing of the survey files by TFGROSS is controlled by a file containing the survey file names; "File Containing Names of LOG Surveys". The default control file name is "INP.TMP". Each record contains either a survey file name or a comment. Comment records are indicated by an asterisk "*" in the first column.

\section{AUDIT TRAIL}

The TFGROSS program can change data values within an individual survey file. A file containing an audit trail of the changes is created each time the program is executed. The default file name is "CHANGES.TXT".

\section{COMPUTED RESULTS}

Numerical values computed by the TFGROSS program are written to a sequential ASCII file with one record for each survey file processed. The default file name is "ANALYSIS.TXT". Each record contains the same number of values. They are:

1 Survey number (1 to $\mathrm{n}$ )

2 Survey date; year and fractional portion (yy.ddd)

3 Survey date; YYMMDD (taken from file name)

Following added when "Locate Contamination Zones" option set to " $Y$ ".

4 Number of data values in the log survey.

5 Percentage of log survey values that are below BKGMAX.

6 Average of the background portion of the survey (AVGBKG). Average of only the survey values that are less than or equal to BKGMAX.

7 One sigma uncertainty of the mean background value. Equation is: SQRT(AVGBKG). Following added when "NET Contamination" depth value entered.

8 PK character flag to identify NET Contamination values follow.

9 Depth location of peak being computed.

10 Maximum survey value if auto search permitted, or the survey value at specified depth if auto search not permitted.

11 Width of SUM WINDOW (feet)

12 NET Contamination [SUM - (AVGBKG*Width_Sum_Window)]

13 One sigma uncertainty of NET Contamination. Equation is: SQRT (NET). 


\section{DATA GAPS}

Two processing parameters control the replacement of data gaps in an individual Dry Well survey. The input parameters are:

"Replace Gaps in Data Values (Y/N): __ Change Values $<=:$ __ "

The program will replace survey data gaps only for probe type "04" at this time. Problems have been encountered for the $1=G r e e n-G M$ and $2=$ Red-GM probe types.

If the program option is activated then each survey is scanned for values less than or equal to the change value (usually +1 ). When a bad value is located it is replaced by the mid point between the previous and following valid value [ (low + high) $/ 2$ ].

The survey file is re-written to disk. A record is written to the Aludit-Trail flle containing:

"CHANGE-VAL, well,log-date,depth,old-val,new-val"

\section{LOCATE CONTAMINATION}

The objective of this program option is to show log surveys that are not consistent with the norm.

Three processing parameters control the output to an ASCII file that high-lights intervals within each survey of suspect or definite contamination (high gamma-ray activity). The input parameters are:

"Locate Contamination Zones $(\mathrm{Y} / \mathrm{N})$ :

"ASCII File Showing Contamination Zones :

With Values $>$ : ___ (BKGMAX)

NOTE: $\quad$ The numerical value above indicates the upper limit of background gamma-ray activity and is used by other options in the TFGROSS program. The default background (BKGMAX) is 50 counts/secord.

The output file (default file name: "HI-ZONES.TXT") contains one record for each Dry Well survey processed. The file is intended for visual inspection and is not formatted for automatic processing. Each record contains:

1 Survey number (1 to $n$ ).

2 Survey date; year and fractional portion (yy.ddd).

3 Survey date; YYMMDD (taken from file name).

4 Depth of the maximum count rate.

5 String of 75 characters (150-ft survey depth) with each character representing the maximum gamma activity for its corresponding $61 \mathrm{~cm}$ ( 2 foot) interval. The character will be either (space, period, or digit[1-9]). The digit represents the number of times the measured gammaray value is above the (BKGMAX). The equation is: SQRTI (cps(i)-BKGMAX) / BKGMAX ]. If the computed value is positive but less than 1 then a period (.) is output. If the computed value exceeds 9 then it is reset to 9 . 
This program option also computes values that are added to the "ANALYSIS.TXT" output file. They are:

4 Number of data values in the log survey.

5 Percentage of log survey values that are below BKGMAX.

6 Average of the background portion of the survey (AVGBKG). Average of survey values that are less than or equal to BKGMAX.

7 One sigma uncertainty of the mean background value. Equation is: SQRT(AVGBKG).

\section{DEPTH SHIFT}

The depth location of an interval of high gamma-ray activity can vary by several feet from survey to survey. Normalizing the surveys to a constant depth by adding a constant to the depth values of a survey improves evaluation of the computed results. Three program parameters control the depth shift option. They are:

"Depth Align Contamination Peaks to Depth :

"Mode: $1=$ Lead Edge, $0=$ Peak, $-1=$ Trail Edge :

"Peak Search; Depth Range (def $=20 \mathrm{ft}) \mathrm{ft}$ :

An entry of zero (0) for the "Depth Align Contamination Peaks to Depth" turns the option OFF.

The "Peak Search; Depth Range" parameter defines a search window width above and below the entered depth for locating the desired contamination peak. The total window with is twice the entered value.

There are three alignment modes. All modes are limited to survey values that exceed BKGMAX. The alignment modes are:

1 Leading Edge. The rate of change between current and previous depth values is monitored. The maximum rate of change is used to select the survey depth that will be reset to the desired depth. The option tracks only the first leading edge and will not accidently select a higher rate of change from a lower contamination zone.

0 Peak. Selects the depth with the maximum survey value within the peak search window "Peak Search; Depth Range".

-1 Trailing Edge. Selects the depth with the largest negative rate of change.

The depth shift amount is computed as a constant between the observed and desired depth. The depth shift is applied, the survey file is re-written to disk, and an AUDIT-TRAIL record is written that contains:

"Depth-Align, log-date, from: depth, to: depth, amt: $x x x "$ 
WHC-SD-ENV-TI-001, Rev, 0

\section{COMPUTE CONTAMINATION}

Three program parameters control calculation of the net contamination in a survey. The parameters are:

"CaIculate NET Contamination at Depth :

"Depth Samples in FIXED SUM WINDOW (0=Auto)

"Peak Search; Depth Range $(0=$ no search) :

An entry of zero (0) for the "Calculate Net Contamination at Depth" will turn the option OFF.

The "Peak Search; Depth Range" option permits the program to search within the depth window (above and below the entered depth) for the maximum survey value. An entry of zero (o) turns off the search option. After the maximum survey value is located, the "SUM WINDOW" is established (1/2 above and $1 / 2$ below) to integrate (i.e., sum) the survey count activity.

An entry of zero (0) for the "FIXED SUM WINDOW" permits the program to extend the integration (summation) until the survey gamma values fall below BKGMAX.

The "NET Contamination" is sum of the gamma-ray activity (fixed or automatic window width) minus the background activity (AVGBKG * number of samples within the window).

The TFGROSS program adds the following values to the "ANALYSIS.TXT" record for each survey processed:

8 PK character flag to identify NET Contamination values follow.

9 Depth location of peak being computed.

10 Maximum survey value if auto search permitted, or survey value at specified depth if auto search not permitted.

11 Width of SUM WINDOW (feet)

12 NET Contamination [ SUM - (AVGBKG*Width_Sum_Wirdow)]

13 One sigma uncertainty of NET Contamination. Equation is: SQRT (NET). 
WHC-SD-ENV-TI-001, Rev. 0

Figure C-1. TFGROSS Input Parameters.

TFGROSS: Analyze TANK-FARM Gross-Gamma Log Suryeys Program Rev 1.00 May 9,1996

File Containing Names of LOG Surveys: INP.TMP AUDIT-TRAIL File to Record Changes : CHANGESc.TXT Computed Results File Name : ANALYSIS.TXT

Replace Gaps in Data Values $[Y(N): Y$ Change Values $<=: \underline{1}$

Locate Contamination Zones $[Y / N]: Y$ With Values $>: 50$ ASCII File Showing Contamination Zones : Hl-ZONES.TXI

Depth Align Contamination Peaks to Depth: 0 . Mode: $1=$ Lead Edge, 0=Peak -1=Trail Edge : 0

Peak Search; Depth Range [def $=20 \mathrm{ft} f \mathrm{ft}$, ]

Calculate NET Contamination at Depth : 64 Depth Samples in FIXED SUM WINDOW [0=:Auto] 3 Peak Search; Depth Range [ $0=$ no search] : 3

Debug $[0=$ None 3=Max $\}$ NOT-USED 0

F1d=Run Program Esc=Abort Program 
WHC-SD-ENV-TI-001, Rev. 0

This page intentionally left blank. 
WHC-SD-ENV-TI-001, Rev. 0

\section{APPENDIX D \\ SX 104-03 DRY WELL LOG DATA ANALYSIS}

This report is analysis of surveillance logs from borehole 41-04-013. The name of the computer directory contains the data is SX-104-03. The report in this appendix uses the SX-104-03 notation.

This appendix is a self-contained report that has its own figures and appendix.

D-1 
WHC-SD-ENV-TI-001, Rev. 0

This page intentionally left blank.

D-2 
WHC-SD-ENV-TI-001, Rev. 0

SX 104-03 Dry Well Log Data Analysis

\section{INTRODUCTION}

Dry well logging has occurred at the tank farms over the last 20 plus years. The original goal of this data collection was the detection of leaks from the tanks. Analysis of this data in light of recent advances in comparison techniques can shed additional light on the movements of contaminants in the earth formations surrounding tanks used for waste storage. Use of recently implemented high resolution downhole spectroscopy instrumentation defines boundaries for extrapolation of observed movements projected into the past 20 years. This report will examine one well, SX 104-03, and determine the types of changes observed by the dry well logging data.

\section{DRY WELL LOG DATA}

The instrumentation used is scintalator gamma ray detection, and the collection system is a gross count collected approximately every 1 foot increment with in the depth of the vell. Figure 1 shows one such $\log$ collected on March 11, 1975, for the SX 104-03 well. The counts observed in the contaminated zone centered at $20 \mathrm{ft}$ reach a maximum reading of 1800 counts. The remainder of the log intervals are at background levels due to the naturally occurring potassium, uranium, and thorium found in the soils surrounding the borehole. These observed counts average 30 cour's, a factor of 60 reduction over the highest reading found in the zone at $20 \mathrm{ft}$.

Subsequent $\log$ data were recorded in this well near a frequency of 1 week. The reproducibility of the depth points from $\log$ run to log ron is not adequate for comparison of any given log to another. This problem is compounded by the course sampling every one foot. 4 thin zone will not necessarily be sampled for a given $\log$ nu at the maximum reading for the interval of activity. The logging program did not have as a goal the fine sampling since only notification of gross changes were targeted. For these reasons, analyzing each $\log$ data set for the maximum observed reacling is not as accurate as finding the zone grade value near $20 \mathrm{f}$. Thus all the counts over this higher rciding interval were summed for each $\log$ data measured. Over the course of the Iogging program of neasly 20 years, the depth reference was observed to drift as much as $3 \mathrm{ft}$. This change is most likely caused by errors in the absolute depth reference and not any movement of the contaminant in the earth surounding the borcholc. This will be illuminated when a decay structure is compared to the overall readings for the 20 years.

Comparison of this log data with the data collected March 25, 197: for this same well, does not lead to any definitc conclusions. The sampling accuracy in both time and depth result in statistical deviations that are much larger than any possible clianges observed for this 14 day time lapse. However, analysis- of each log run over the 20 year time frame can greatly improve the statistical precision of any definition of possible contaminant changes.

In addition to the sum of the counts over the interal of maximum rcading, an average background level was obtained. This value was found by averaging counts for the enture well log data for all intervals with values below 50 counts. This background level is caused by the nat ural radioactive elements in the earth soils. These background levels only change on geologic time scales and can therefore be used to determine the instrument stability for the dry well logging program.' In fact, these background readings can be used to "re-calibrate" or normalize different instruments to the same readings. However, this is outside the scope of the present investigation. It is sufficient for this data set to simply verify using these background readings that the instrumentation used on this well was stable and constant within statistical precision.

SX 104-03 Analysis by Three Rivers Scientific 
WHC-SD-ENV-TI-001, Rev. 0

\section{Data Analysis}

Therefore, each log data were analyzed to produce two numbers for the date of each log. The counts in the observed contaminated zone were added throughout the interval of observation. Likewise, a single average background count was determined for the remainder of the log where the levels were below 50. Figure 2 contains this data set for the time from Jan 29, 1975 until Nov 22, 1995. Dry well log data from 1982 to 1985 were not made available for this analysis. Note that the background count rate is plotted on the second axis on the right and is significantly lower than the contaminant zone count rate. This data has not been corrected for any isotope decay, but simply shown as observed. The reasonable consistency of the background levels speak well for the instrumentation stability over this 20 year period, and several versions of instruments were used to collect the data. In fact, most of the observed scatter is due 10 instrument variances and not just statistical variances due to counting statistics. Any error analysis of a data set includes counting statistics and instriment variances. The total observed variances is the precision of the data or entire system, and this number is the error that is used to analyze the data.

The logging frequency for this well is on the order of once per weck. As can be seen in fig 2 , the changes in the contaminant zone count rate is slow compared to this logging frequency. This enables the measurement of the observed variances by performing a simple toot mean square, tms, over every 5 consecutive log data sets. An rms value is computed every two $\log$ reading before and after the reading of interest. These five values produce the rms or an observed standard deviation. These data are plotied in fig 3. The obsened total system variance starts near 190 counts in 1975 and reduces to about 90 in 1995. These variances correspond to relative enrors of $5 \%$ to $7 \%$ for each individual contaminant reating in each log. Counting statistics only would yield a value of relative error near $2.5 \%$ to $3.5 \%$. The higher observed relative cror is consistent with added sources of error duc to instrumentation. This same phenomena is also observed for the average background values. The line in fig 3 is a simple linear regression and has no physical meaning. It is shown only for reference.

Filtering the original data over this same five point nunning average is also possible and produces nuch less variation. The consistency and high frequency of the data allows this filtering with no loss of detail information.

If the radionuclide contaninant was not changing concentration in a given interval of a well, then, the observed count rate would decay exponentially to natural background levels. The last points have count rates well above natural background levels and therefore still contain significant levels of contaminant. A. single exponential decay does not fit the data for this well. This fact is clear after a simple examination of the data on a semi-log plot; there are large systematic differences froin a single exponcntial. The next step in analysis is to consider a two decay component condition. That is, the presence of two isotopes with different decay rates.

Two or more isotopes with different decay rates would yield a two con ponent decay structure with time. Clearly, the faster decaying isotope would reduce faster eventually leaving only the slower component. All of these details depend upon the relative concentrations, and individual decay rates. However, two closely matched decay rates produce results with only one observable deray rate within statistical precision limits. Appendix A contains a description of such a case where Eu-154 and Co-60 would be present together yielding a single observed decay rate somewhat less than the inlicrent Eu-154 lalf life of 8.5 years and more than the Co-60 half life of 5.27 years.

Gross count rate data only will often yield data that cannot be used to determine the presence of a given isotope. If the system is very simple, i.e. a single isotope, and no change in concentration, then the observed data would yield a single exponential to a constant background. This case could be argued to delineate the isotope in question. The gross count rate data of this well over the past 20 years does not allow this type of conclusion. 
Towards the end of 1995, a high resolution spectroscopy logging system was nu in this well. This data can be used to tag the isotopes and their decay rates for a valid projection of the observed gross count rate back in time. The observation was $\mathrm{Cs}-137$ at $5 \mathrm{pCi} / \mathrm{g}, \mathrm{Eu}_{\mathrm{u}}-154$ at $2.7 \mathrm{pCi} / \mathrm{g}$, and $\mathrm{Co}-60$ at threshold reading of $0.3 \mathrm{pCi} / \mathrm{g}$. The units here are in activity levels, therefore, the total gamma ray emission from the three isotopes can be approximated by the percentage of activity for each radionuclide. This yields nearly 5/8th Cs-137 contribution and $3 / 8$ th contribution from a combination of Eu-154 and Co-60. These two isotopes are grouped since they have similar decay rates. (Refer to Appendix A.) It is true that the absolute intensity of total gross count rate from equal activities of $\mathrm{C}(\mathrm{A}-60$ and $\mathrm{Cs}-137$ would produce different weighted fraction for the total observed gross count rate. Data analysis could be performed to assay these isotope to gross calibration efficiency factors, but is beyond the present scope of this work. Since the conclusion drawn here does not significantly depend upon the precise percentage of each contribution, these factors are adequate starting points for a least squares fit for activity decay. Simply fix the decay rates at the precise values determined from the high resolution spectroscopy and fit for the levels and relative mixtures that would generate the observed total count rate.

A natural first attempt to analyze data from this well would be to fit the observed gross count rate with two exponentials fixed at the observed levels at the end of 1995. Such a fit does not match the data within its variance. The conclusion is un-mistakable changes in isotope concent rations over the past 20 years. In fact, there appear to be increases in the contaminant concentrations as recently as 1990 . Figure 5 contains this type of least squares fit compared to the filtered data. The solid line is the fitted sum of the two components, (one Cs-137 and the other is the effective combination of Yu-154 and $\mathrm{Co}-60$ ). The dashed line is the Cs-137 component, and the dotted line is the other. Note the relative slow character of the Cs137 over the combination Eu/Co component. This also represents a ma:imum possibility for the Cs-137 since the obsenable nearly reaches the Cs-137 both at the present timt: and in 1986. Most likely, the absolute level of $\mathrm{Cs}-137$ is somewhat lower than shown here. It is clear "hat no combination of these two components can match the observed data within its statistical precision.

Note that the constant background was ignored in this fitting in order to simplify the math, since its effect on these large values is ncgligible. Also, no deadime corrections were applied since this could not account for the relatively rapid changes observed. (It must atso be noted that characterization of the dead time for the logging instruments is not known.) A dead time correction could only change the observed count rates in one direction, either to larger count rates or smaller count rates, but not both.

A least squares fit for a two component exponential structure does not yield an adequate fit within statistical precision. Since no reasonable fit results, concentration levels of onc or more of the possible contaminants have changed beyond radioactive decay. Determining which isotope changed concentration is not uniquely possible. There are many possible combinations of whanges that could produce the observed gross count rate with time. For cxample, it is possible that the $\mathrm{Cs}-137$ contaminant was immobile for these 20 years, and the Eu- $154 / \mathrm{Co}-60$ changed in accordance with the observed data. Under this scenario, we observe an increase in Eu-154/Co-60 near 1977. Subsequently, this combination isotope(s) significantly reduced somewhere between 1983 and 1986. Likewise, this combination contaminant has increased from 1986 to 1994, where a drop then occurs to the present. This oscillatory systematic deviation from the best two exponential fit rulcs out problems with lack of a dead time correction. Also, this count rate is not noticeable large for a significant dead time problem unless the instrumentation is very slow.

The data do not allow the conclusion that the Cs-137 contaminant did nol move. However, if the scenario is played that Cs-137 concentration levels changed, then the relative anounts of Eu-154 and/or Co-60 ehanged even more than depieted above. Simply subtract the Cs-137 component line from the total gross count rate observed 10 see changes in any isotope over and above the $C s-137$ that has remained constant.

The conclusion that contaminant concentration levels have changed over the past 20 years is not hindered by the gap in the data for the years 1982 to 1985 . This data if added to the analysis might help determine the specifics of what changes have occurred over the past 20 years. 
A more reasonable projection of activity into the past would be to fix the present close to the relative concentrations obscrved and project back and match only the levels at the visy start of 1975 . Then there would be observed a significant increase quickly in late 1975 with relative little change until some time after 1982. Then a significant increase is observed from 1986 until 1994, where contamination levels are presently continuing to decrease beyond simple radioactive decay.

\section{PERSPECTIVE \& CONCLUSIONS}

The Ievels of contaminant concentration in this well are presently not very high, less than $10 \mathrm{pCi} / \mathrm{g}$. Other zones in other wells in and out of the tank farms have shown many times this level of activity. The absolute levels of concentration is not as important as the fact that the level: are showing relatively rapid changes. The question is where is the contaminant coming from, what is the driver, and where is the contaminant going. Guessing that the $\mathrm{Cs}-137$ is not changing in this well nay prove to be invalid if near by well data and analysis show Cs-137 only and experiencing non decay chinges in concentration. Such combination analysis of other wells would significantly add to the understanding of the processes occurring in the carth surrounding the $\operatorname{tank}(s)$.

The data taken by tank farms personnel in the dry wells can be used to ascertain level changes in concentration that dictate the vadose zone is not in a static state. As has be:n seen, the sensitivity of this data to concentration changes is excellent. The data simply requires analysis in light of the systematic changes that can occur in a quantitative description. Likewise, instrumentalion errors can be present and yet not hinder analysis given correct analysis techniques that properly account for hardware deficiencies.

\section{APPENDIX A "Two closely matched decay rate componenis"}

Observation of radioactive decay is generally subject 10 gamma ray counting statistics. At some level of instrumentation and sampling time, two isotopes of different decay rates are indistinguishable from a single component of decay. One cxample of application to the Hanford Site is Eu-154 and Co-60, with inherent decay half lives of 8.5 and 5.27 years, respectively. High resolution spectroscopy could easily resolve these isotopes, but a gross gamma ray intensity system at poor statistical precision would not necessarily resolve these components on the basis of observed total count rate decay.

Consider a mixture of 1 part Eu-154 and 1/10 part $\mathrm{C} 0-60$; this happens to nearly match the condition observed in late 1995 by HPGe logging system in the dry well SX 104-03. A purely theoretical description of this hypothetical decay can be constncted by adding the two components. These summed values can then be fitted for a single exponential decay. The difference from a fitted single exponential can be compared to the true sum of the two components. Figure $\mathrm{Al}$ is a plot of the results for a backward 20 years time frame. The intensity used for the $\mathrm{Co}-60$ is 1000 and for the $13 \mathrm{u}-154$ an intensity of 10,000 , referenced to time zero. Figure A2 shows this same difference in percent of the 20 ycar activity levels. The average ertor is on the order of .025 of $1 \%$. The fitted decay rate to the sum of these two components yields a half life (effective) of 8.4 years, somewhat less than the Eu-154 value of 8.5 years. However, it is clear that a single exponential is statistically indistinguishable from the sunı of the two decay components over this 20 year time frame, for the instrumentation used to $\log$ this diy well. In the body of the document covering the $\mathrm{SX} 104-03$, the quoted system observable relative variance was on the order of $5 \%$.

This same conclusion is reached even if the two components have equal sisength. Figure A3 is the result for this condition. Notice that the maximum observable error is $2 / 10$ of $1 \%$. In this case, the effective 
WHC-SD-ENV-TI-001, Rev. 0

fitted half life is 7.72 ycars, which is not a linear average of the two decay components. The sum of the two components is not a single exponential, but the deviation from a single exponential is $0.2 \%$ at the maximum value over the 20 year time period. 


\section{SX 104-03 Log Data Date: 3-11-75}

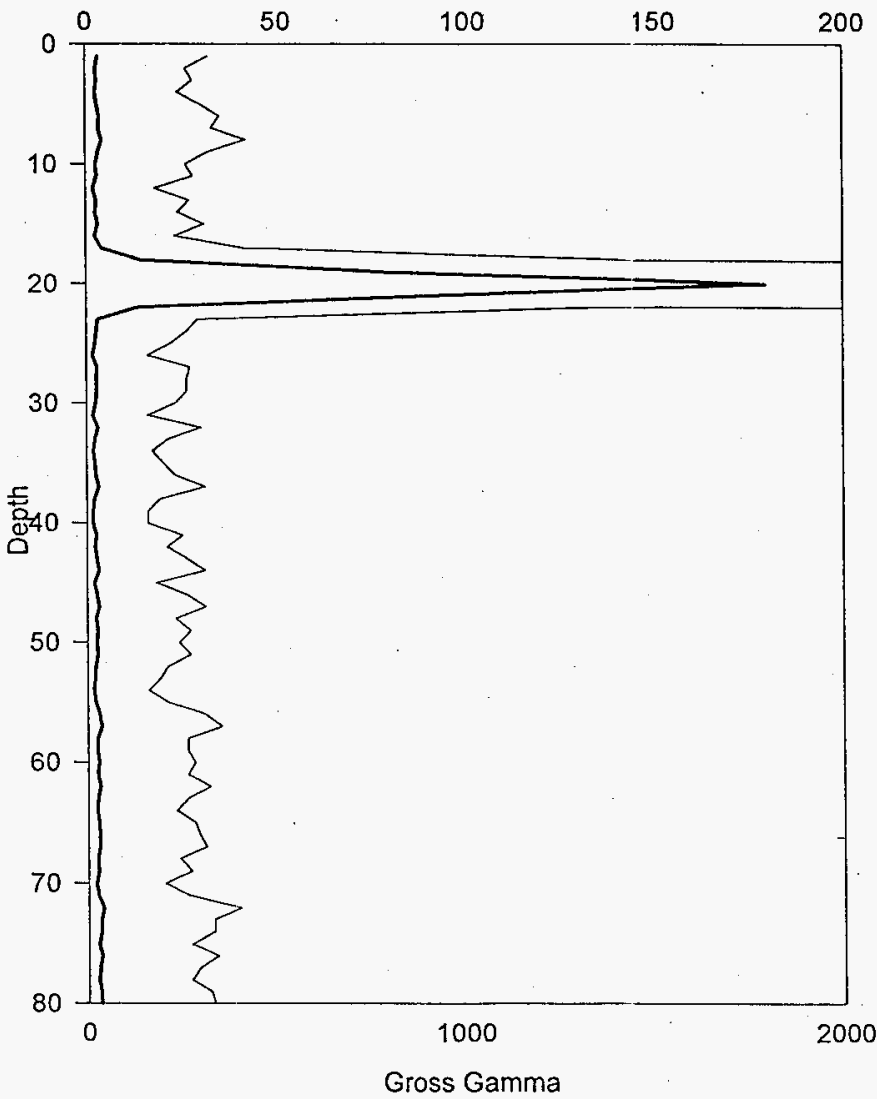

Figure 1. Gross gamma ray data for dry well $104-03$ of $S X$ tank farm. The fine line is scaled 0 to $200 \mathrm{c} / \mathrm{s}$, and the thick line is scaled 0 to $2000 \mathrm{c} / \mathrm{s}$. 
WHC-SD-ENV-TI-001, Rev. 0

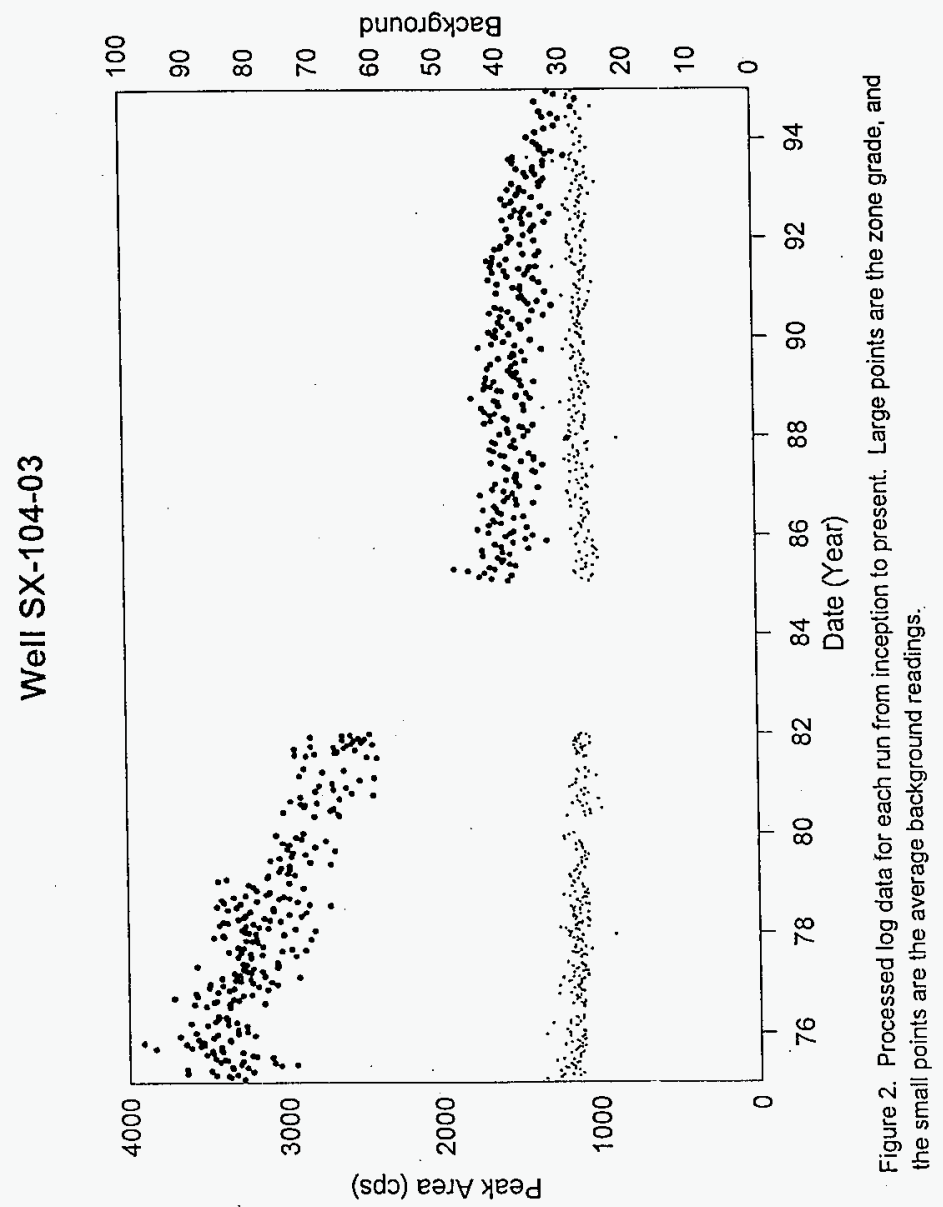

SX 104-03 Analysis by Three Rivers Scientific 

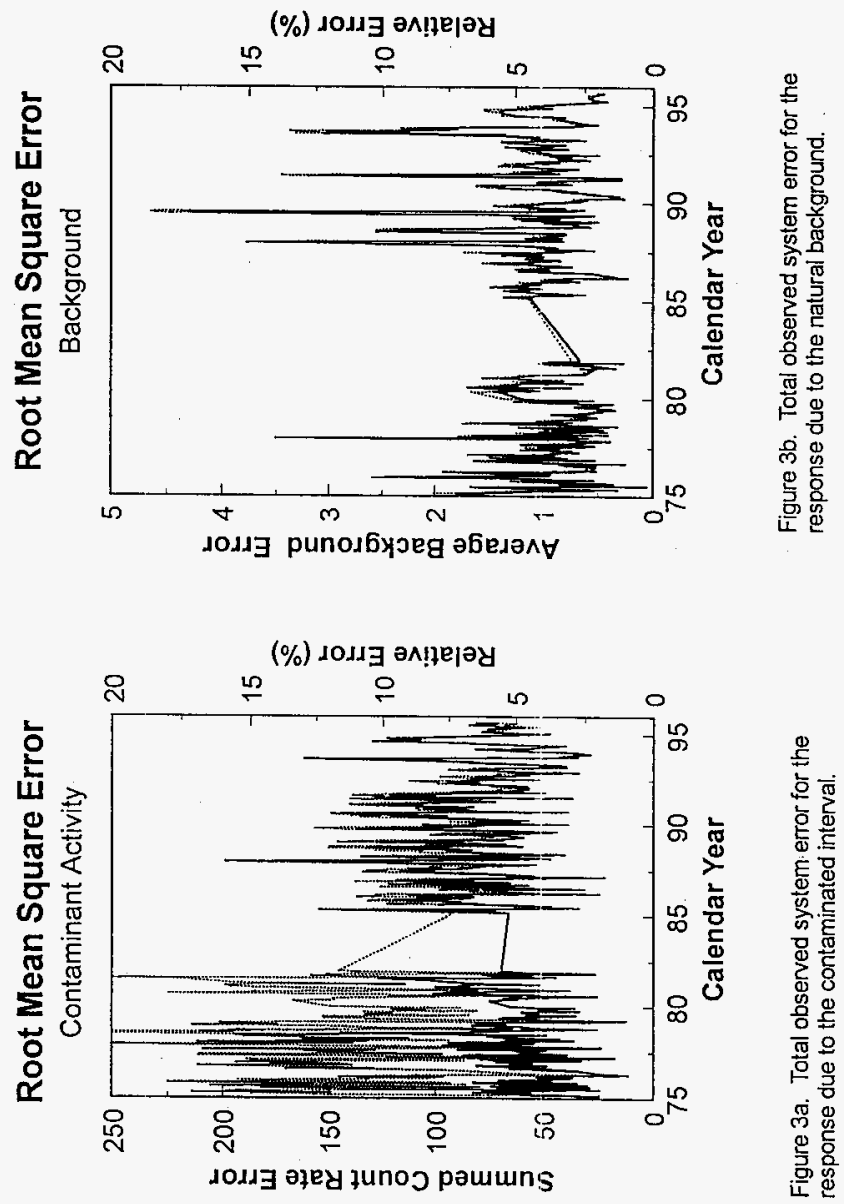
WHC-SD-ENV-TI-001, Rev. 0

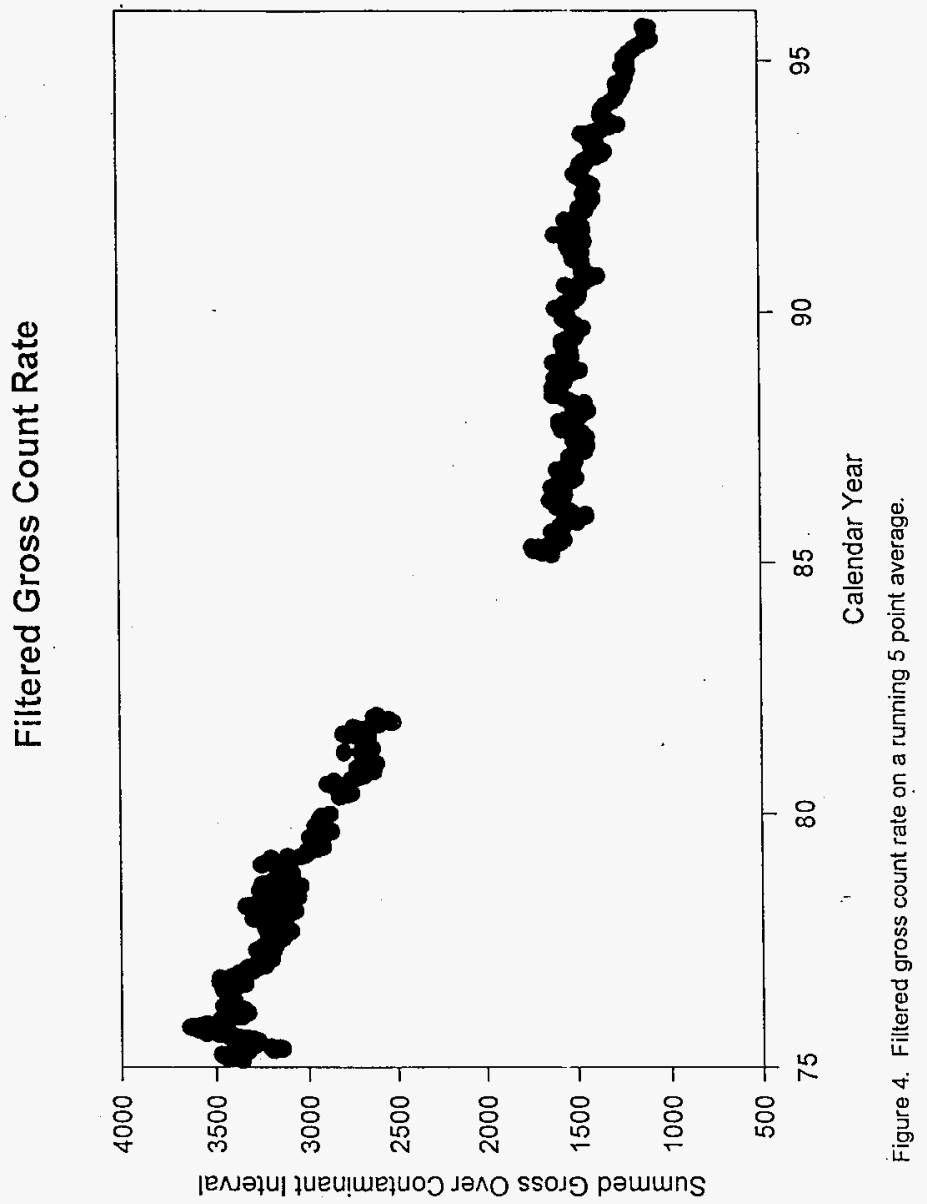

SX 104-03 Analysis by Three Rivers Scientific 


\section{Least Squares Fit}

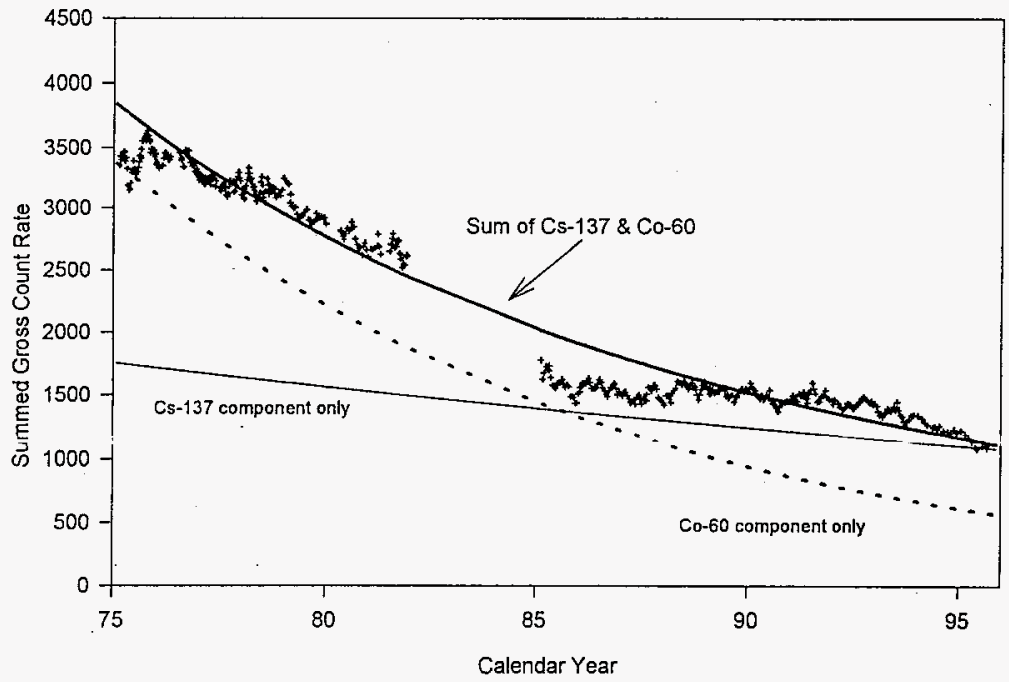

Figure 5. Least squares fit and components compared to contaminant interval gross count rate. 

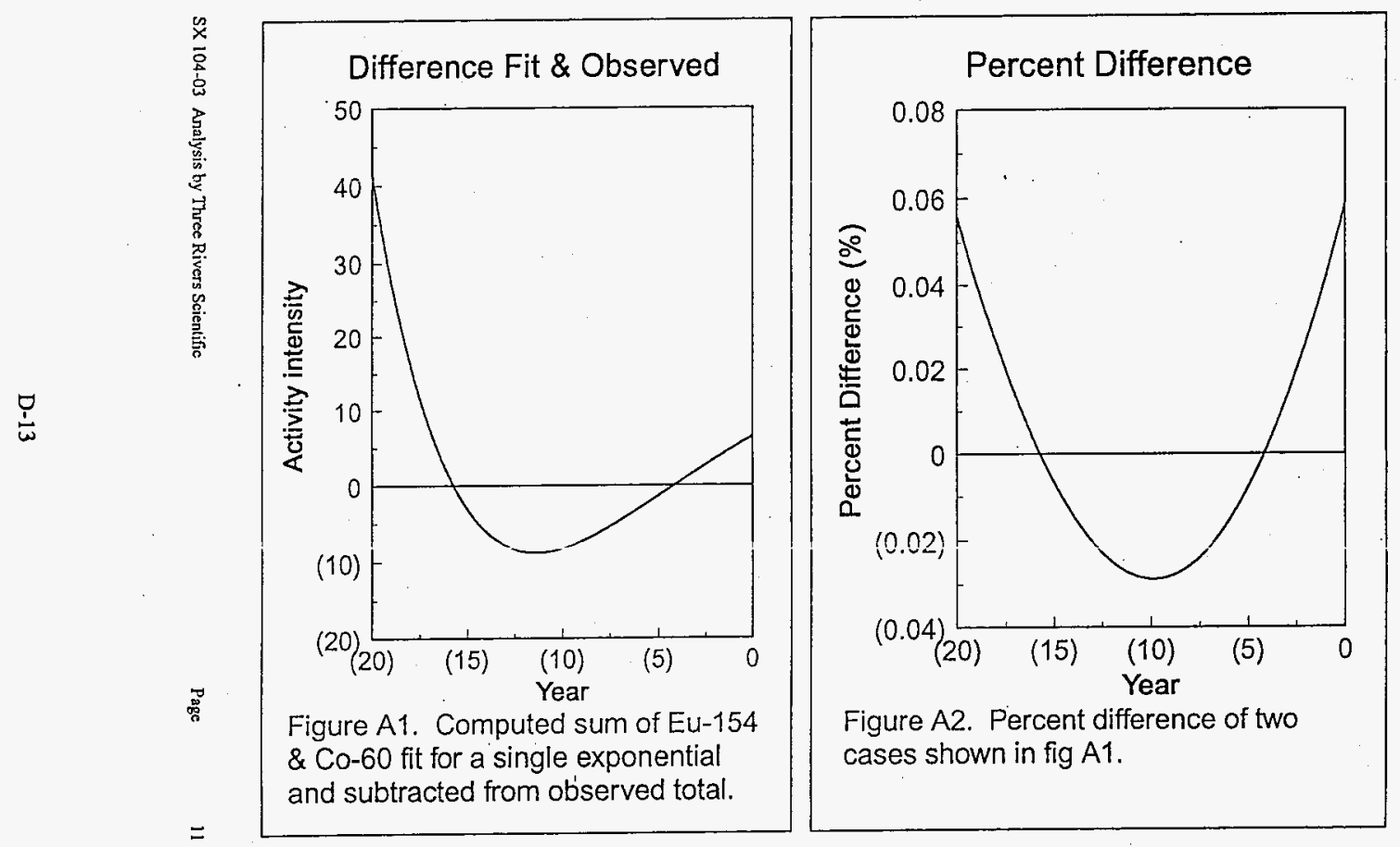

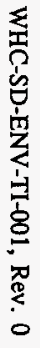


WHC-SD-ENV-TI-001, Rev. 0

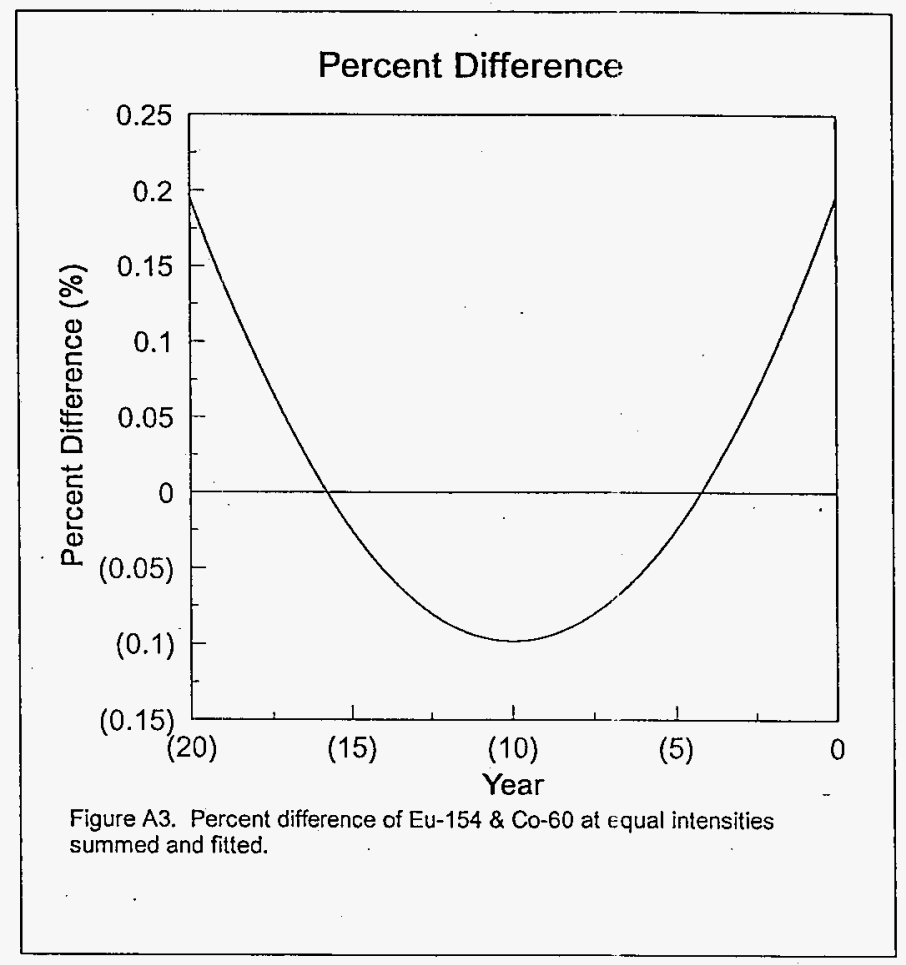


WHC-SD-ENV-TI-001, Rev, 0

\section{APPENDIX E \\ SX 110-08 DRY WELL LOG DATA ANALYSIS}

This report is analysis of surveillance logs from borehole 41-10-08. The name of the computer directory contains the data is SX-110-08. The report in this appendix uses the SX-110-08 notation.

This appendix is a self-contained report that has its own figures. 
WHC-SD-ENV-TI-001, Rev. 0

This page intentionally left blank. 
WHC-SD-ENV-TI-001, Rev. 0

SX 110-08 Dry Well Log Data Analysis

\section{INTRODUCTION}

Dry well logging has occurred at the tank farms over the last 20 plus years. The original goal of this data collection was the detection of leaks from the tanks. Analysis of this data using recent advances in comparison techniques can shed additional light on the movements of contaminants in the earth formations surrounding tanks used for waste storage. This report will examine one vell, SX 110-08, and determine the types of changes observed by the dry well logging data.

\section{DRY WELL LOG DATA}

The instrumentation used is scintalator gamma ray detection, and the collection system is a gross count collected approximately every 1 foot increment over the depth of this well. Figure i shows one such $\log$ collected in March 1975, for the SX 110-08 well. The counts observed in the contaminated zone located between 50 and $60 \mathrm{ft}$ reach a maximum reading of 180 counts per second. The remainder of the $\log$ intervals are at background levels due to the naturally occurring potassium, uranium, and thorium found in the soils surrounding the borehole. These observed counts average 3j counts, a factor of 6 reduction over the highest reading found in the zone at $55 \mathrm{ft}$.

Analysis of these log data must reconcile the level of technology existing for the instrumentation. There are several sources of error. Depth control is dependent upon both the luman setting of the reference or zero point as well as the mechanical accuracy of depth encoding. Poor sampling frequency in sample time and depth resolution affect the observable variance in any readings. The log data were collected for 1 sec at each 1 foot depth point.

The combination of poor depth control or absolute accuracy with gross changes in depth are particularly troublesome for analyzing thin zones. Thicker zones with detail structure will also appear to vary significantly from one log to another, even if the radionuclides are not changing in the earth formations. For these reasons, the use of the maximum reading in a well $\log$ is not as precise as adding the observed readings for an interial detcrmined to contain gamma emituing contaminants. This zone averaging then produces a more repeatable total than a shifting high point that may have been jumped over by a I foot increment in sample point.

The series of logs run for this well were examined and found to tot demonstrate any appreciable broadening or indications of downward contaminant migration. The system precision does not rule out small changes in depth profile of the contaminant. As will be seen, there is definite indications that the concentrations did significantly change beyond natural decay. Therefore, the most probable conclusion is that the contaminant moved laterally away from the borehole.

Each dry well log was processed to produce two values used in this in estigation. First, the sum of the count rates over the interval centered at $55 \mathrm{ft}$. was recorded as a function of the log daie. Second, the average background value for the remainder of the $\log$ was recorded for the $\log$ date. The average reading was determined by summing all intervals where the values did not exceed $50 \mathrm{c} / \mathrm{s}$ and dividing by the number of readings used for this sum.

The value of the background reading is crucial for the assessment of the stability of the instrumentation used to collect the data. The dry well logging program used several di:ferent instruments. If any given instrument was more efficient than another, then, the observed background would also demonstrate this difference. Instrument drift in the effective energy threshold for the gross count rate would also be evidenced by changes in the observed natural background. It may even be possible to adjust the readings 


\section{WHC-SD-ENV-TI-001, Rev. 0}

in the contaminated interval by normalizing to the average background firr any given log as a method to "re-calibrate" the instrument or instruments for their different efficiency. However, this processing is beyond the scope of work for this investigation. The background reading is simply used here to determine that the data is stable and useful for time decay analysis.

Subsequent log data were recorded in this well near a frequency of 1 weck until 1979 were the frequency was reduced. The reproducibility of the depth points from $\log$ run $1.0 \mathrm{log}$ run is not adequate for comparison of any given log to another. The logging program did not $r$ ave as a goal the fine sampling since only notification of gross changes were targeted. However, the high frequency of logging does allow for reasonable time decay structure.

\section{Error Analysis}

Figure 2 contains the summed count rate over the contaminated interval at $55 \mathrm{ft}$ plotted as a function of the log date from Jan 15, 1975 until Jun 10,1994. Note that the background count rate is plotted using the second axis on the right and is scaled lower than the contaminant zone count rate. This data has not been corrected for any isotope decay, but simply shorn as observed. The reasonable consistency of the background levels speak well for the instrumentation stability over this 20 year period, and several versions of instruments were used to collect the data. In fact, most of the observed scatter is due to instrument variances and not just statistical variances due to countings statistics. The error analysis includes counting statistics and instrument variances. The total observed variances is the precision of the data or entire system, and this number is used to assess the data.

It is possible to measure the total system precision since the logs were ru!n so often. A rapid one year half Jife would result in a $1.3 \%$ drop in gamma activity over a time lapse of cne week. If the system variance is larger than this systematic decline, then, three subsequent log readings can be considered as three repeat values of the same condition. Therefore, a root mean square of each reading using the previous and the future values was calculated. This data is shown in figure 3a. Likewise, the relative variance is plotted using the second axis scaled in \%. The observed relative variance for the log data for this dry well program is then near $5 \%$ for the first year and rises to a value betwcen $35 \%$ and $40 \%$ for the remainder of the program. This will become important when the detailed decay structure analysis is brought out. The $35 \%$ to $40 \%$ variance is reasonable for the last 19 years, since the activity levels are near background levels and there is very little signal.

Figure 3 b contains a similar calculation of the observed variance for the average background processed for each log data set. Here, the variance is relatively stable at $4 \%$. The enror is much smaller since most of the log depth intervals are used in the computation of the average background; where as, only a ferv points are used for the summied gross in the interval initially tagged as contaminated. After the fifth year of logging, (1980), there exists a decline in the observed background of about $10 \%$. This change is of no real consequence since the activity has dropped to background levels and no other activity in this earth zone is observed.

\section{Decay Structure Analysis}

The changes in count rate for the contaminated interval is relatively rapid. Figure 4 is a plot of the same data shown in figure 2, but only for an eight year time span. It appears that the intensity levels starting in 1975 drops to nearly $1 / 2$ after one year. Speculation is therefore that the contaminant is Ru-106 with a half life of 368 days. The next step in analyzing this well is to examine the gross count rate on a semi-log plot. This investigation then reveals that there is not a single exponential. Figure 5 is a plot of the data on a semi-log scale, as well as screral exponential decay structures down to a background level. 
The rapid drop in count rate of the contaminated interval of this well that occurs from the stan of 1976 to 6 months later is not the signature of a two components decay structure. A two component decay structure is concave upwards, asymptotically reaching a constant on such a plot as shown in figure 5 . Regardless of the exact identification of the isotopes, this behavior of count rate with time is the signature of concentration changes other than natural radioactive decay. Therefore, other analysis techniques must be employed in order to determine what events occurred in the earth formations surrounding the borehole.

Ru-106 is known to be one of the contaminants released to waste sites and held in tanks. Few other isotopes of known existence at Hanford are close to the 1 year half life of Ru-1 06. Proceeding on the basis that the observed count rate is due to Ru-106 yields the different decay sinuctures shown in figure 5 . Given this half life, then, only intensity is a variable and statements can be made concerning the changes in concentration. The solio line at the bottom is a least squares fit to the constant background after 1983, The other three decay curves are at the 1 year half life, but at different starting intensities.

A least squares fit for an exponential plus a background was performed for the data staring 7 months after 1976 to 1985 . The resulting decay rate for this fit is a 0.91 ycar half life, very close to the expected 368 day half life of Ru-106. System variance could account for the differerce from the fit value of half life. It must be remembered that the observed activity for this period is close to background levels.

Since the change of count rate with log date is not a two exponential (or more) system, the assumption of Ru-106 is strengthened. For this reason, a fixed 1 year half life decay structure is called for and demands changes in concentration. Following this approach, a one year half life decay is plotted in figure 5 in order to fit the observed data for the lst year of the logging program. It is not possible to obtain a good fit over just this first year, and thus, two different levels of $\mathrm{Ru}-106$ are indicated even for the first year of operation for this well. In fact, if a least squares fit is performed for the sata over only this year, the resultant decay rate is 0.73 year half life. The logging program relative error measured for this time interval is 5\%. On this basis, it is clear that either 1) the isotope existing at $55 \mathrm{ft}$ in 1975 is not Ru-106 or 2) Ru-106 concentration levels are changing during 1975.

High resolution spectroscopy log data on this well does not exist during the years that are of use. Present $\log$ data collection would not yield any valuable information, since the activily has dropped to background levels. Basically, there are limitations to information from only gross ganima logging data. However, there are pieces of information that is possible using the available data. Namely, there was a significant concentration of gamma emitting contaminant in the depth interval at $55 \mathrm{ft}$ during the first half of 1976.

\section{PERSPECTIVE \& CONCLUSIONS}

The levels of contaminant concentration in this well are presently at background levels. The most significant fact is that the levels are showing relatively rapid changes. The question is where did the contaminant come from, what is the driver, and where did the contaminant go. AJalyzing dala from other wells might help to shed some light on the mechanisins occurring in the vadose zone in and around the SX tank farm. Such combination analysis of other wells would significantly add to the understanding of the processes occurring in the earth surrounding the tank(s). Likewise, use of later state of the art high resolution spectroscopy logging instrumentation would lead to less speculation and more definitive conclusions

The decay rate of Ru-106 is rapid and therefore no recent detection is expected. The last 12 years did not experience any changes in isotopes. However, this does not mean that the earth formations have not experienced migrations driver, but that the isotope has decayed to levels that are undetectable. It is significant that during the time that $\mathrm{Ru}-106$ was visible that concentration levels were seen to change. This is a relatively short time window to view changes, and yet they were i iewed. Sampling only over a short time and viewing changes statistically leads to the conclusion that chariges are probable. 


\section{WHC-SD-ENV-TI-001, Rev. 0}

The data taken by tank farms personnel in the dry wells can be used to ascertain level changes in concentration that dictate the vadose zone is not in a static state. As has been seen, the sensitivity of this data to concentration changes is excellent. The data simply requires analysis in light of the systematic changes that can occur in a quantitative description. Likewise, instrumentation errors can be present and yet not hinder analysis given correct analysis techniques that properly account for hardware deficiencies. 
WHC-SD-ENV-TI-001, Rev. I)

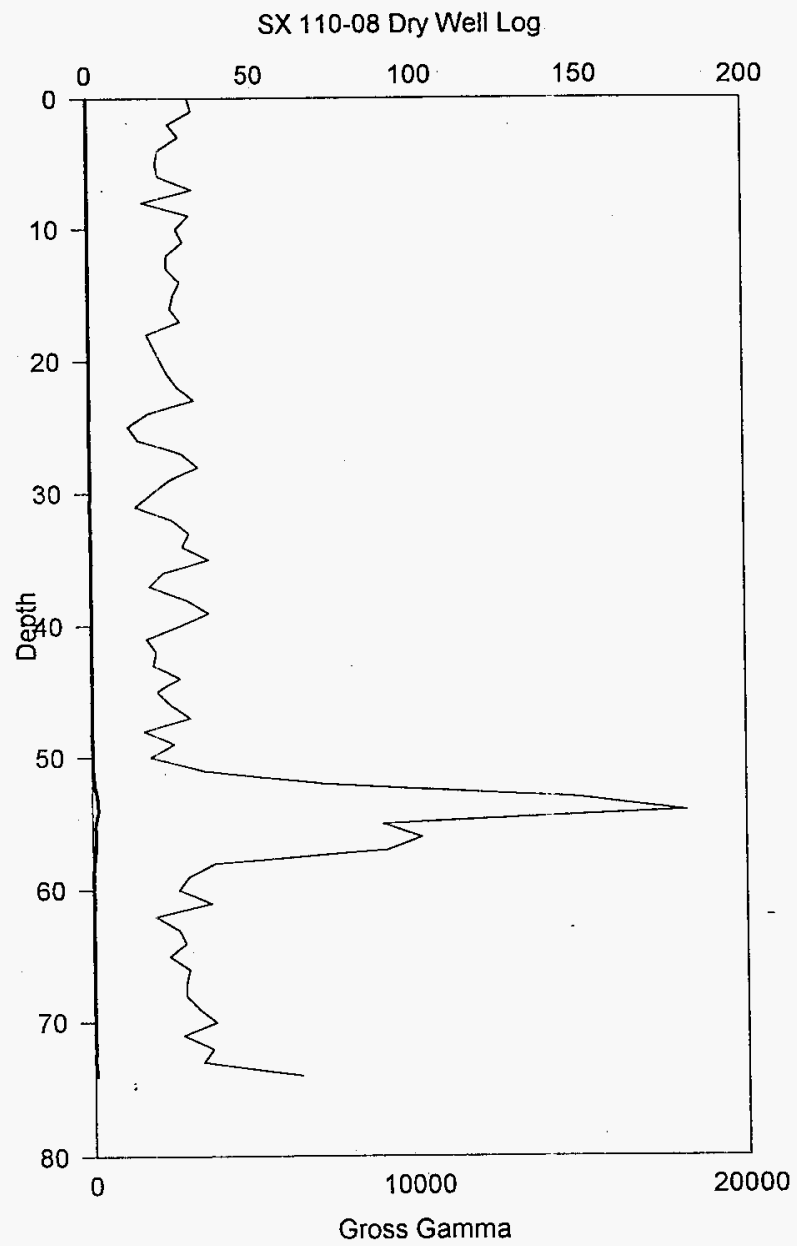

Figure 1. Dry well log data collected in March 1975 
WHC-SD-ENV-TI-001, Rev. 0

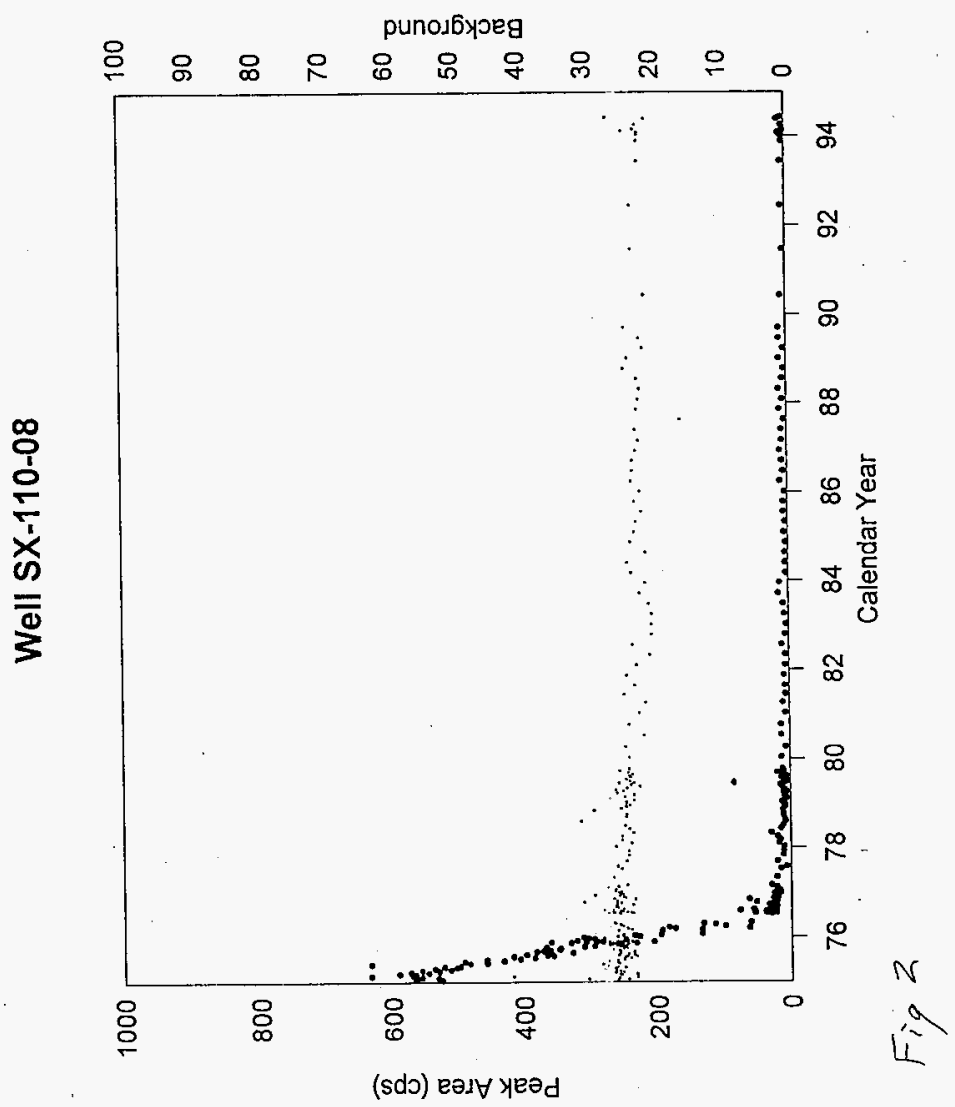


WHC-SD-ENV-TI-001, Rev. 0
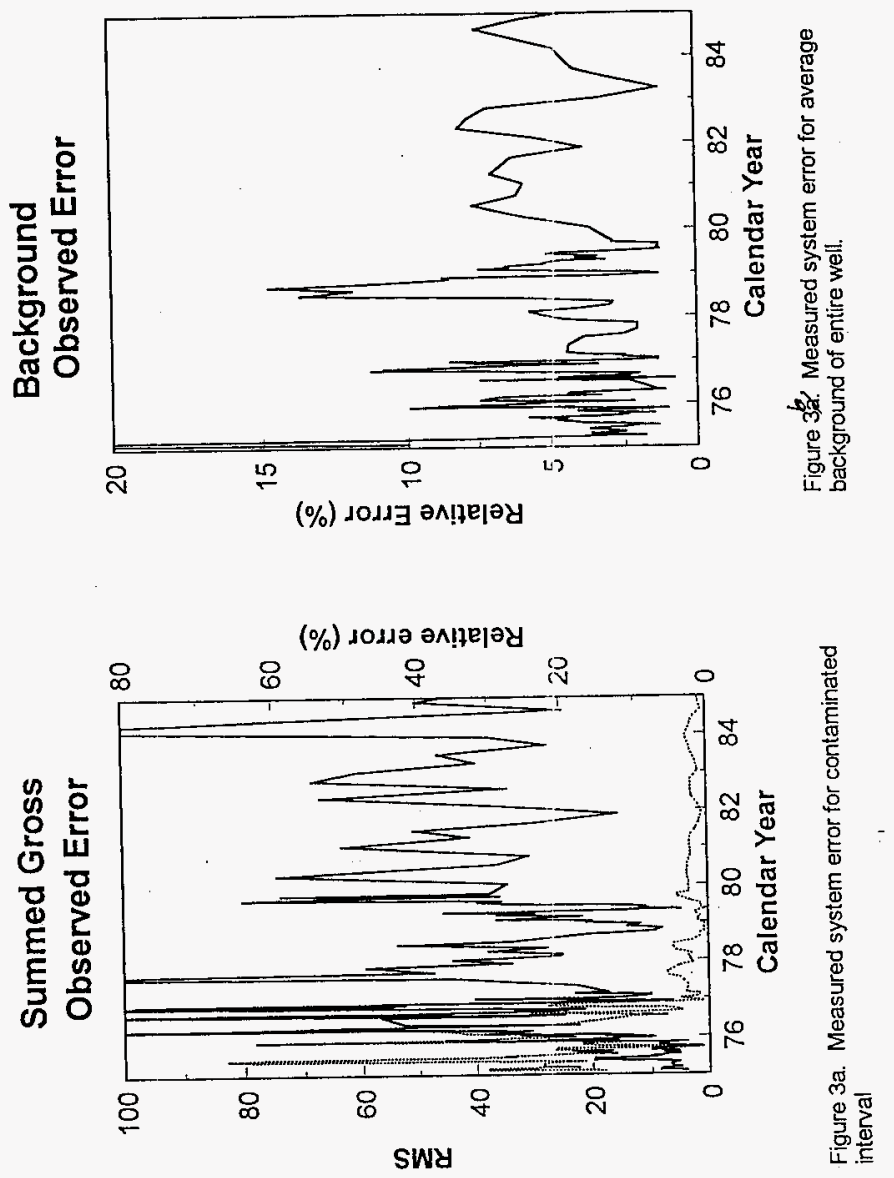
WHC-SD-ENV-TI-001, Rev. 0

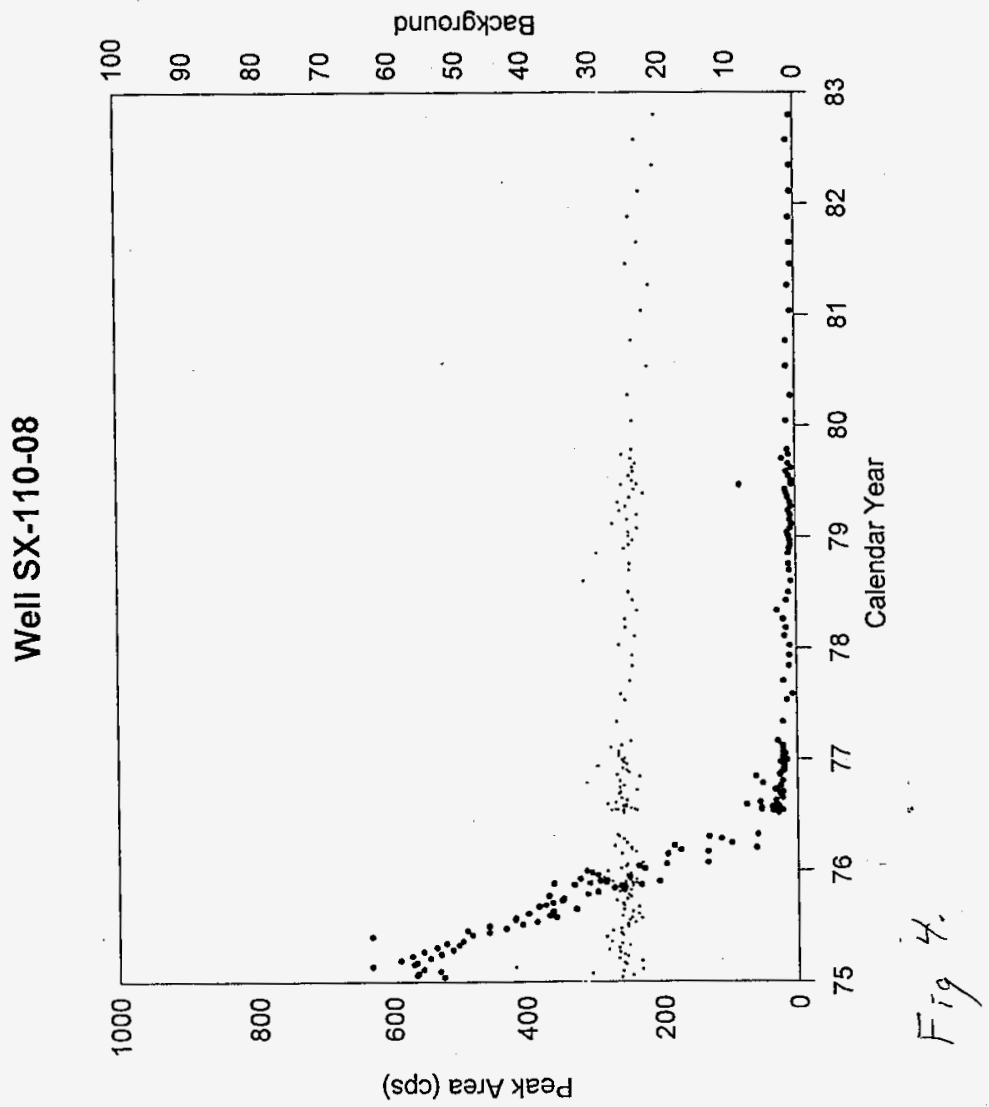


SX Tank Farm Dry Well 110-08

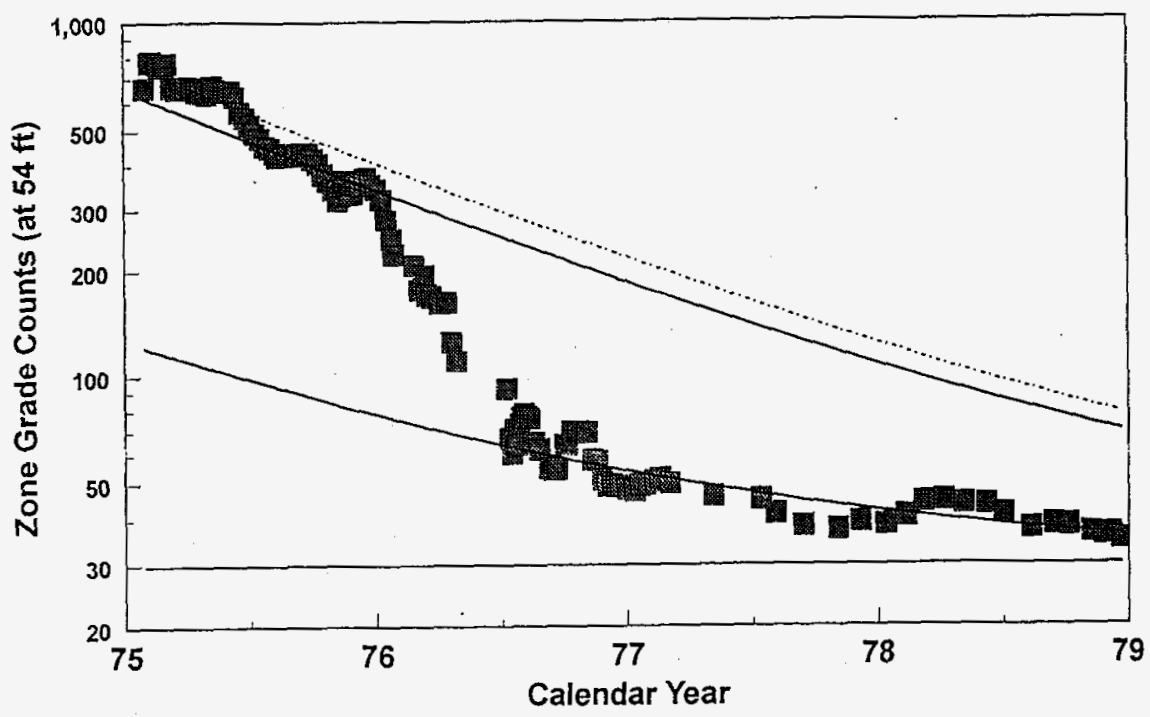

Figure 5. Filtered data compared to several decay structures and a constant background. 
WHC-SD-ENV-TI-001, Rev. 0

This page intentionally left blank.

E-12 